\title{
S-Wave Velocity Structure of the Taichung Basin, Taiwan, Estimated from Array and Single-Station Records of Microtremors
}

\author{
by Toshimi Satoh, Hiroshi Kawase, Tomotaka Iwata, Sadanori Higashi, \\ Toshiaki Sato, Kojiro Irikura, and Huey-Chu Huang
}

\begin{abstract}
The objective of this study is to estimate the $S$-wave velocity structure of the Taichung basin in a near-fault region, which is needed for strong-motion evaluation for the 1999 Chi-Chi earthquake. We have conducted array measurements of microtremors with a total of 12 arrays at four sites and single-station measurements of microtremors at 48 sites in and around the Taichung basin. Based on the Rayleighwave inversion technique using phase velocities estimated from array records of microtremors, we find that a thick layer (the thickness of about 1000 to $1400 \mathrm{~m}$ ) with an $S$-wave velocity of $V_{S} 1100 \mathrm{~m} / \mathrm{sec}$ exists in the east-central part of the Taichung basin. We estimate the thicknesses of sedimentary layers above the preTertiary bedrock at 48 sites to fit calculated peak and trough frequencies of horizontal-to-vertical spectral ratios of Rayleigh waves to observed peak and trough frequencies, assuming the same $S$-wave velocities estimated using array records. The pre-Tertiary bedrock depth was estimated to be about 5 to $6 \mathrm{~km}$ in this region. The estimated thickness of the layer with $V_{S}=1100 \mathrm{~m} / \mathrm{sec}$ is largest in the east-central part of the basin and rapidly decreases to less than $400 \mathrm{~m}$ in the northeastern and western parts inside the basin. The estimated $S$-wave velocity structures reasonably explain arrival time of initial $P$ and $\mathrm{S}$ waves of aftershock records observed by Higashi et al. (2001).
\end{abstract}

\section{Introduction}

The 1999 Chi-Chi earthquake caused severe damage in the near-fault region. To evaluate near-fault strong motions, it is important to estimate source processes and site effects quantitatively. Theoretical evaluation of strong motions and site effects requires information on velocity structures, especially for sedimentary layers above the bedrock. Theoretical simulation of strong motions for the 1994 Northridge earthquake (e.g., Graves, 1996) and the 1995 Kobe earthquake (e.g., Pitarka et al., 1998; Kawase and Matsushima, 1998; Iwata et al., 1998) had shown that site effects caused by the 3D basin structure have an important role in strong motions. However, the literature on velocity structures in the near-fault region of the Chi-Chi earthquake does not provide enough information for theoretical strong-motion evaluation. Therefore we conducted array and single-station measurements of microtremors in and around the Taichung basin, which is the most populated area in the near-fault region, and estimated $S$-wave velocity structures to construct a basin model needed for theoretical strong-motion evaluation.

The exploration method to estimate deep structures using array records of long-period $(>1 \mathrm{sec})$ microtremors was established by Horike (1985) and Matsushima and Okada (1990) after the pioneering work done by Aki (1957). Since that time, it has been extended to estimate shallow structures using short-period $(<1 \mathrm{sec})$ microtremors (e.g., Sato et al., 1991; Tokimatsu and Miyadera, 1992). Based on the successes of these studies, the array method has been applied in recent years to estimate not only shallow but also deep structures to the bedrock using short- and long-period microtremors (e.g., Kawase et al., 1998; Kudo et al., 2000; Satoh et al., 2001a).

Array measurements of microtremors are appropriate to estimate an $S$-wave velocity structure, which is the most influential structure on strong motions. In addition, array measurements of microtremors are less expensive than conventional methods such as reflection and refraction exploration methods to explore deep sedimentary layers. So we conducted array measurements of microtremors at four sites in Tali City inside the basin and estimated the $S$-wave velocity structures below these sites.

Since four sites are not enough to construct a 3D basin model, we then conducted single-station measurements of microtremors at 48 sites in and around the Taichung basin. In previous studies, peak or trough frequencies of horizontalto-vertical spectral ratios (HVRs) of microtremors have agreed with calculated ones of the fundamental Rayleigh 
wave (e.g., Yamanaka et al., 1994; Ishida et al., 1998; Satoh et al., 2001b). In a few basins the bedrock depth has been estimated to fit the calculated peak frequencies (Yamanaka et al., 1994; Satoh et al., 2001c) or trough frequencies (Ishida et al., 1998) of Rayleigh wave to the observed frequencies. Satoh et al., (2001c) constructed a 3D velocity model of the Sendai basin in Japan by interpolating $S$-wave velocity structures estimated from array records of microtremors at six sites by using single-station records of microtremors from 61 sites. They successfully simulated strong-motion records of an earthquake of $M_{\mathrm{J}} 5$ using the 3D basin model. Thus single-station records of microtremors are useful for estimating a spatial basin structure if $S$-wave velocity structures at several sites in the basin are explored.

In this study we estimated the $S$-wave velocity structures at the 48 sites using both peak and trough frequencies of HVRs. Note that our method of HVRs was different from Nakamura's method (Nakamura, 1988). Nakamura's method assumed observed HVRs to be $S$-wave amplification, whereas we fit calculated Rayleigh wave HVRs to observed HVRs. The idea of the method used in this study is the same as in the previous studies referred to earlier (Yamanaka $e t$ al., 1994; Ishida et al., 1998; Satoh et al., 2001c), but they estimated only one parameter, bedrock depth, because they used only one peak or one trough frequency of HVRs. In contrast, we estimated several parameters (thicknesses of six layers) using both several peak and trough frequencies of HVRs in a relatively wide frequency range.

Finally, we examined the initial $P$ - and $S$-wave travel times of strong-motion records of an aftershock (M 5.5) recorded by 10 temporary strong-motion stations (Higashi et al., 2001) to check the validity of the velocity structures estimated from microtremors.

\section{Field Measurements and Data}

Figure 1 shows the locations of the epicenter of the ChiChi earthquake of $M_{\mathrm{W}} 7.6$ and one of its aftershocks of $M$ 5.5 that occurred on 19 October 1999, together with the surface fault traces, most of which coincide with the Chelungpu fault. We plotted the epicenter of the mainshock estimated by Shin et al. (2000) and that of the aftershock estimated by the Taiwan rapid earthquake information release system $(\mathrm{Wu}$ et al., 1997). Figure 2 shows the locations of the array and single-station microtremor observation sites together with the Central Weather Bureau (CWB) strong-motion stations (Shin et al., 2000) and the temporary stations referred to earlier (Higashi et al., 2001) in and around the Taichung basin. The Taichung basin is bounded by the Chelungpu fault on the east and the Changhua fault on the west. Both of these are thrust faults dipping to the east accompanied by anticlinal folds on the hanging wall (e.g., Lee et al., 1996). We conducted array measurements of microtremors at TCU062, TAL001, TAL002, and TCU067 in the middle of October 1999. The four sites are located over Holocene sediments. Stations TAL001 and TAL002 are located near the heavily damaged area in Tali City, where several middle-

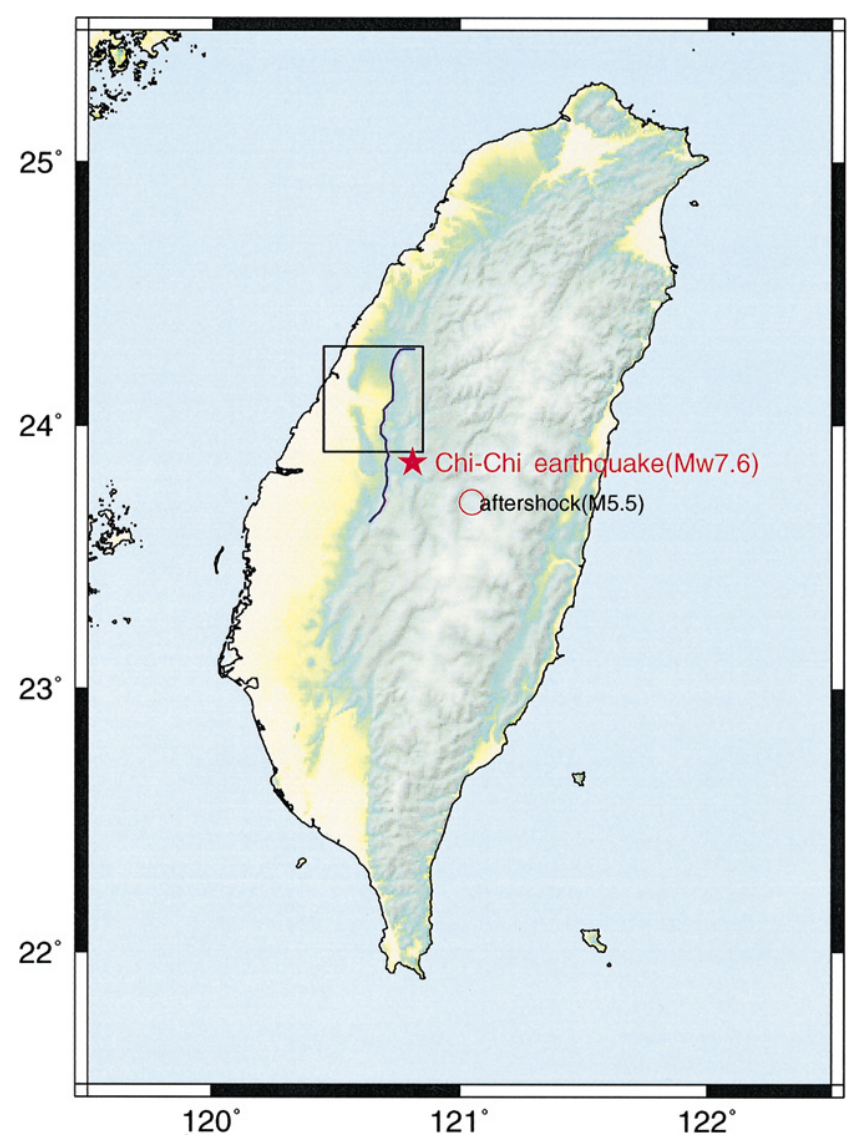

Figure 1. Locations of the epicenter of the ChiChi earthquake of $M_{\mathrm{W}} 7.6$ and one of its aftershocks of $M$ 5.5, which occurred on 19 October 1999, together with the surface fault traces, most of which coincide with the Chelungpu fault (blue line). Rectangle denotes the studied region.

rise buildings have collapsed during the Chi-Chi earthquake. At these two sites we also conducted aftershock observation (Higashi et al., 2001). Stations TCU062 and TCU067 are CWB strong-motion stations, although the mainshock was not recorded by TCU062. The peak ground acceleration of the east-west (EW) component at TCU067 during the ChiChi earthquake was about $490 \mathrm{~cm} / \mathrm{sec}^{2}$, and the peak ground velocity integrated from the acceleration record was about $100 \mathrm{~cm} / \mathrm{sec}$. In the middle of February 2000, we conducted single-station measurements of microtremors at 48 sites including $23 \mathrm{CWB}$ strong-motion stations in and around the Taichung basin. The single-station measurements were conducted basically along one north-south line (NS) and two EW lines (EW-1 and EW-2) with a spacing of 1 to $3 \mathrm{~km}$ across the Taichung basin.

Array and single-station measurements of microtremors were done using portable instruments. One set of instrument was composed of an overdamped moving coil type threecomponent accelerometer developed by Kudo (1998), an amplifier, and a 24-bit digital recorder. The accelerometer had flat amplitude from 0.07 to $140 \mathrm{~Hz}$. The accuracy of the internal clock was within $1 \mathrm{ppm}$ and was corrected by the 


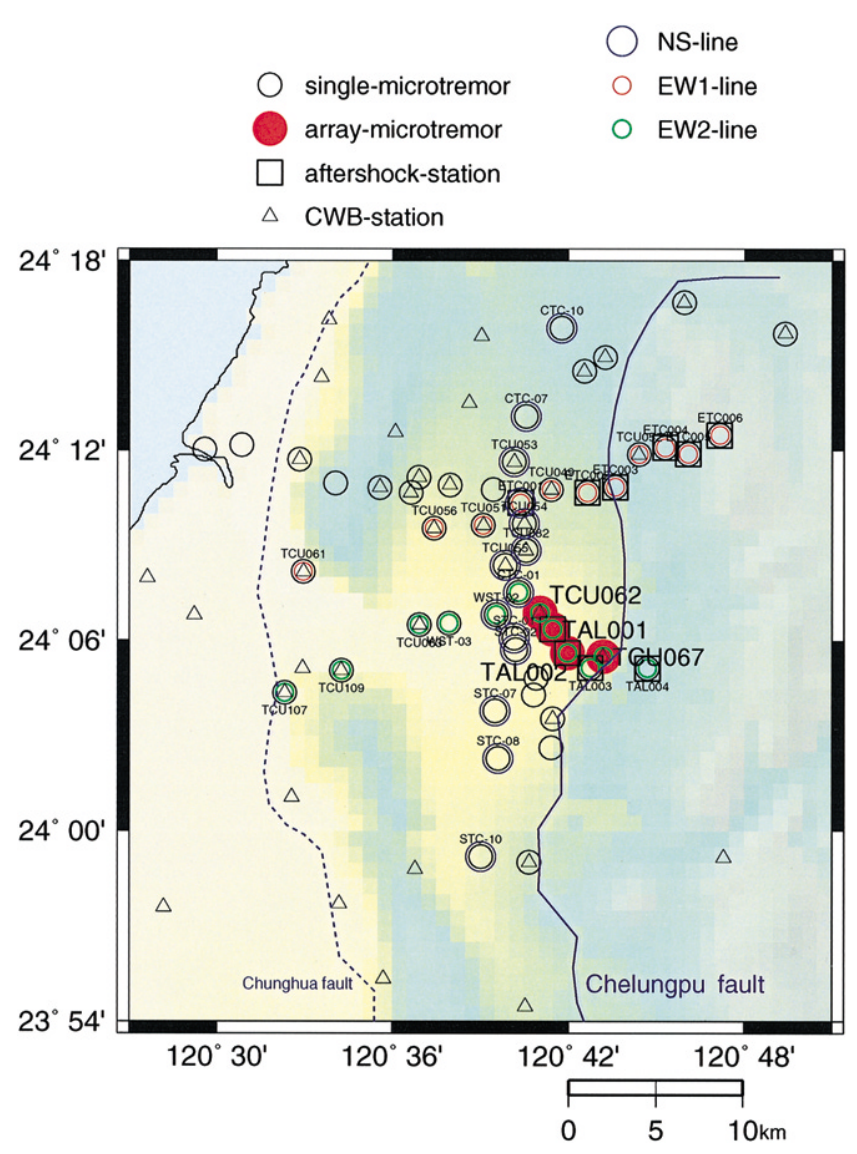

Figure 2. Locations of the array (red big circles) and single-station (black open circles) microtremor observation sites together with the CWB strongmotion stations (triangles) (Shin et al., 2000) and aftershock strong-motion stations (squares) (Higashi et al., 2001) in and around the Taichung basin. The HVRs at stations along the NS line, the EW1 line, and the EW2 line are shown in Figure 12.

Global Positioning System (GPS) before each measurement. The timing accuracy from GPS correction was within $1 \mathrm{msec}$. Starting and ending schedules of measurement were set before the measurement using portable personal computers. We measured microtremors at the 4 array sites with a total of 12 arrays in six days. The array size and number of instruments for each array are listed in Table 1 . The radii of $S, M, L$, and $X$ arrays were 20 to $25 \mathrm{~m}, 40$ to $80 \mathrm{~m}, 130$ to $260 \mathrm{~m}$, and about $700 \mathrm{~m}$, respectively. In Figure 3 we show array configurations of $S$ and $M$ arrays at TAL002. We tried to set up the instruments such as shown in Figure 3a, but the configuration of larger arrays tended to be distorted as in Figure $3 \mathrm{~b}$ due to obstacles such as buildings and roads. We brought seven sets of instruments, but one set did not work properly for the later half of the measurements. Two or three sets of 15-min observations with a sampling frequency of $100 \mathrm{~Hz}$ were performed for each array. A high-cut filter of $10 \mathrm{~Hz}$ was used for $S$ - and $M$-array measurements, while that of $5 \mathrm{~Hz}$ was used for $L$ - and $X$-array measurements. The relative coordinates of stations were measured by measuring
Table 1

Array Size and Number of Stations

\begin{tabular}{clccc}
\hline & & $\begin{array}{c}\text { Smallest } \\
\text { Station } \\
\text { Separation } \\
(\mathrm{m})\end{array}$ & $\begin{array}{c}\text { Largest } \\
\text { Station } \\
\text { Separation } \\
(\mathrm{m})\end{array}$ & $\begin{array}{c}\text { Number } \\
\text { of } \\
\text { Stations }\end{array}$ \\
\hline \multirow{2}{*}{ TCU062 } & $S$ array & 12.5 & 43.3 & 6 \\
& $M$ array & 25.0 & 86.6 & 6 \\
TAL001 & $L$ array & 106.7 & 449.4 & 6 \\
& $S$ array & 12.5 & 43.3 & 7 \\
TAL002 & $M$ array & 25.0 & 141.6 & 7 \\
& $L$ array & 69.5 & 237.5 & 6 \\
& $X$ array & 317.4 & 1192.1 & 6 \\
& $S$ array & 10.0 & 34.9 & 7 \\
& $M$ array & 19.8 & 61.2 & 7 \\
& $L$ array & 84.0 & 227.6 & 7 \\
& $S$ array & 21.7 & 40.4 & 5 \\
& $M$ array & 35.0 & 84.0 & 6 \\
\hline
\end{tabular}

tapes for $S$ and $M$ arrays and calculated from latitude and longitude observed by a differential GPS for $L$ and $X$ arrays. The relative station location accuracy was a few meters for the differential GPS. At 48 single-station microtremor sites, we observed microtremors for 15 min with a sampling frequency of $200 \mathrm{~Hz}$ and a high-cut filter of $30 \mathrm{~Hz}$.

Figure $4 \mathrm{a}$ and $\mathrm{b}$ show Fourier acceleration amplitude spectra at the center station of the $S$ array at each site. Here, observed records were divided into time segments of 40.96 sec in length by overlapping the half of the window length, and the Fourier amplitudes were averaged over the time segments after removing a few time segments clearly contaminated by instrumental or locally generated noise. Horizontal spectra are geometric means of NS and EW components. Both horizontal and vertical spectra have clear troughs in the frequency range from 1 to $2 \mathrm{~Hz}$. For comparison we show Fourier acceleration amplitude spectra of vertical components observed inside the Los Angeles and San Fernando basins in the United States (Kawase et al., 1998) and those inside (OKIN) and outside (TAMA) the Sendai basin in Japan (Satoh et al., 2001a) in Figure 4c. Since Kawase et al. (1998) and Satoh et al. (2001a) observed velocity records, we calculated acceleration spectra by multiplying velocity spectra by the circular frequency. In the frequency range from 0.2 to $0.5 \mathrm{~Hz}$, the amplitudes inside the Taichung basin were much larger than those observed at the other sites. Such a high-amplitude level of long-period microtremors is helpful for estimating a deep basin structure.

\section{Inversion of $S$-Wave Velocity Structures Using Array Records of Microtremors}

\section{$f-k$ Analysis}

We divided the observed records of vertical components into time segments of $40.96 \mathrm{sec}$ in length for $S$ - and $M$-array 


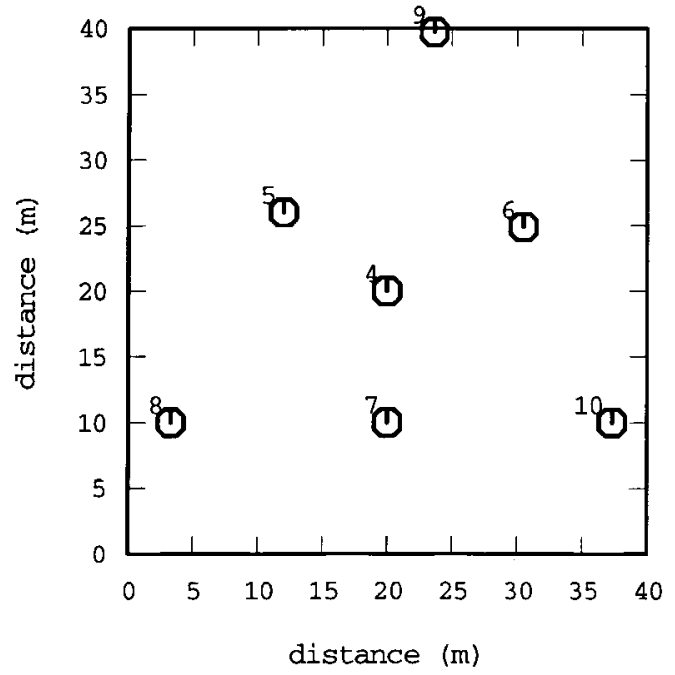

(a) S-array

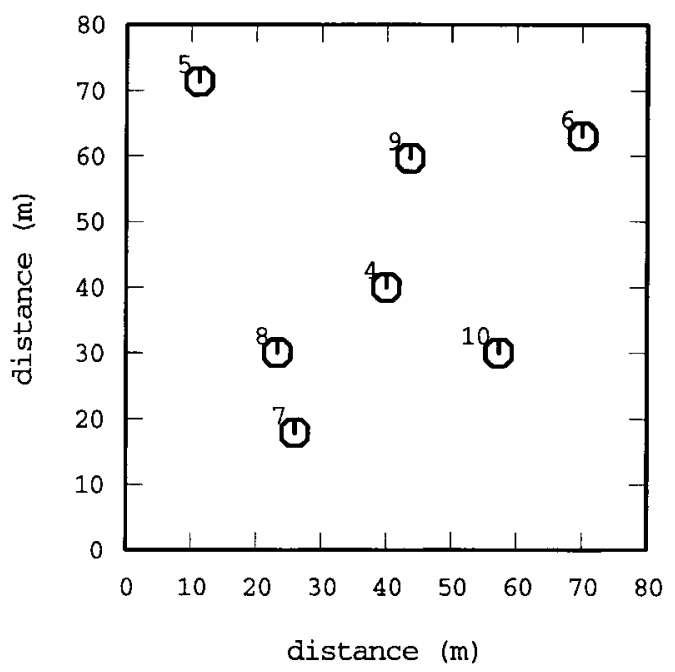

(b) M-array

Figure 3. Array configurations of (a) $S$-array and (b) $M$-array at TAL002. The number near the station denoted by circle in is the station number.

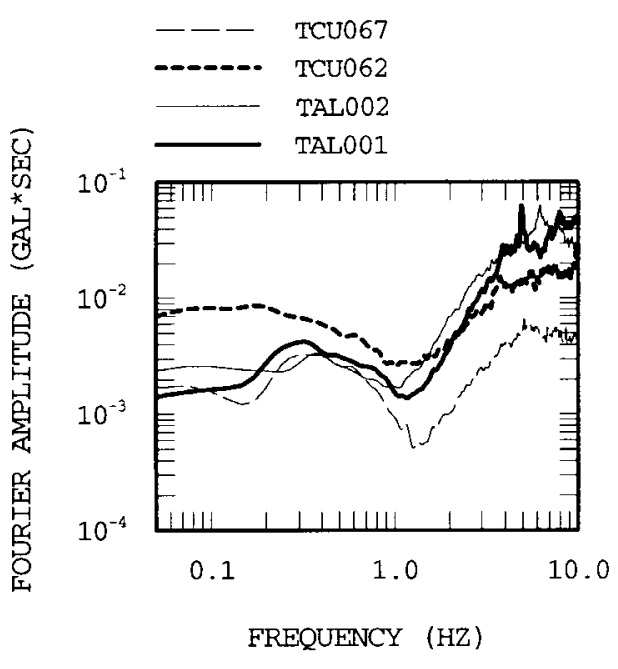

HORIZONTAL COMPONENTS

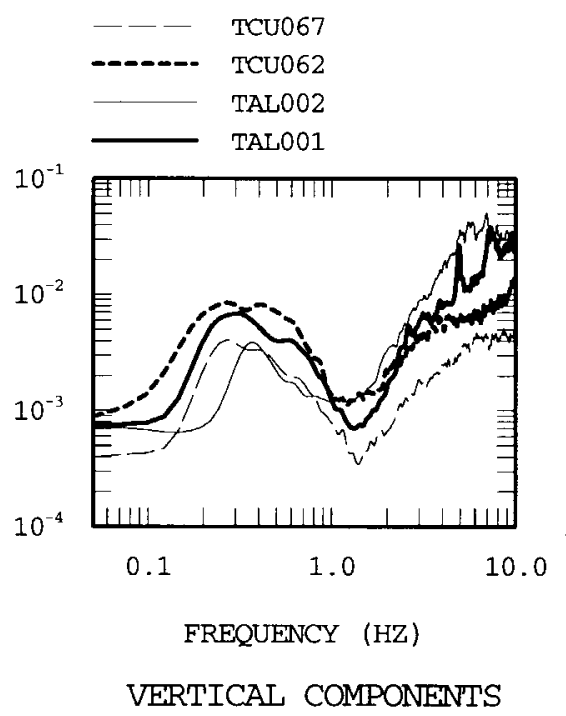

(b)

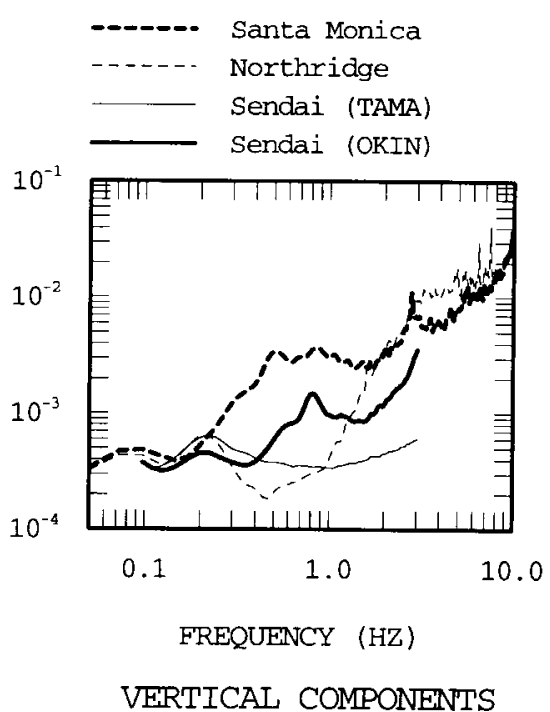

(c)

(a)

Figure 4. (a) Fourier acceleration amplitude spectra of horizontal components at the center station of $S$-array at four sites in the Taichung basin. (b) Fourier acceleration amplitude spectra of vertical components at the center station of $S$-array at four sites in the Taichung basin. (c) Fourier acceleration amplitude spectra of vertical components observed inside the Los Angeles and the San Fernando basin (Kawase et al., 1998) and those inside (OKIN) and outside (TAMA) the Sendai basin (Satoh et al., 2001a).

records and $81.92 \mathrm{sec}$ in length for $L$ - and $X$-array records by overlapping the half of the window length. After removing a few time segments that had been clearly contaminated by instrumental or locally generated noise, we estimated phase velocities by $f-k$ (frequency-wavenumber) spectral analysis based on the maximum-likelihood method (Capon, 1969). Figure 5 shows examples of $f-k$ spectra using micro- tremor data from TAL001. The $f-k$ spectra were calculated at $101 \times 101$ grid points at each frequency. The phase velocity was estimated from the wavenumber of the maximum peak in the $f-k$ spectrum. Since the maximum peaks were searched within the wavenumber windows set by us a priori, minimum phase velocities were limited, but maximum ones were not. The phase velocity of the Rayleigh wave is less 

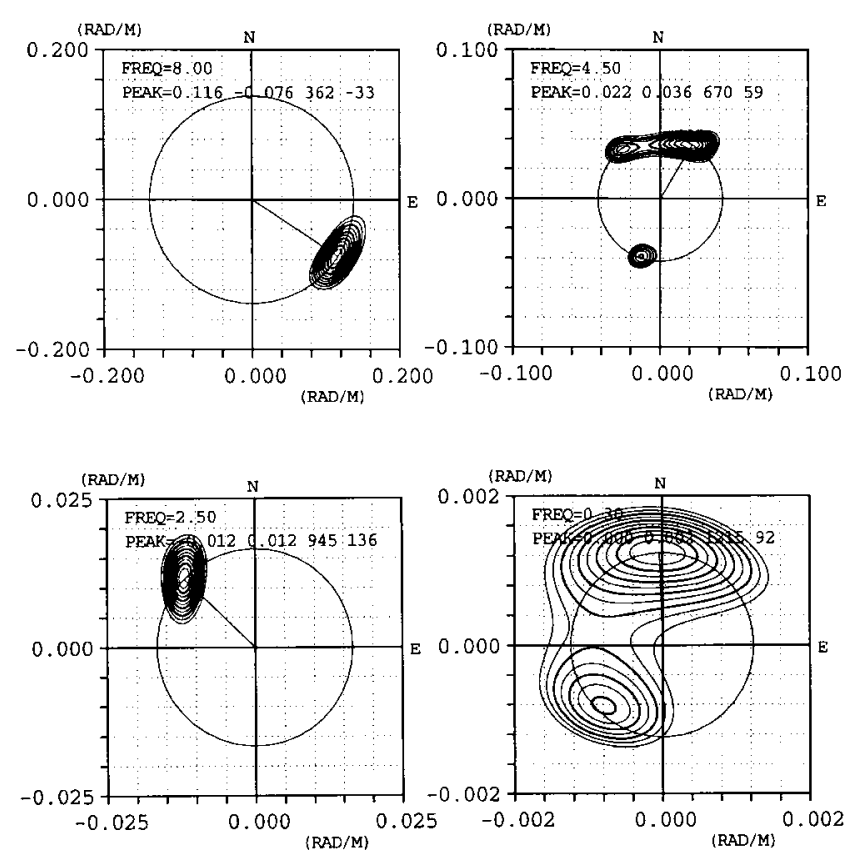

Figure 5. The $f-k$ spectra using observed data at TAL001. The number after "FREQ" means frequency in Hz. The numbers after "PEAK=" mean the wavenumber in the east $(\mathrm{E})$ direction, wavenumber in the north $(\mathrm{N})$ direction, the phase velocity in $\mathrm{m} / \mathrm{sec}$, and the propagation direction counterclockwise from the east in degree. The phase velocity is estimated from the frequency and the wavenumber of the maximum peak in the $f-k$ spectrum. The $f-k$ spectra at $8.0 \mathrm{~Hz}$, $4.5 \mathrm{~Hz}, 2.5 \mathrm{~Hz}$, and $0.3 \mathrm{~Hz}$ are calculated from records observed by $S, M, L$, and $X$ arrays, respectively.

than the $S$-wave velocity, so we exclude phase velocities higher than $4.5 \mathrm{~km} / \mathrm{sec}$. We also excluded unreliable phase velocities based on Thompson's test (Thompson, 1935) with the significance level of 5\% and took a logarithmic average over the reliable phase velocities.

The number of instruments ranged from 5 to 7 as shown in Table 2, so we examined the effects of the number of instruments on average and standard deviation of phase velocity using $M$-array records at TAL002. Figure 6 shows the average and the logarithm of the standard deviation of phase velocities at the frequencies of $4.0,4.5$, and $5.0 \mathrm{~Hz}$, which were the frequencies used for the following inversion analysis. The horizontal axis shows the number of removed instruments (See Fig. 3b). When there were five instruments (two instruments were removed), the standard deviation became larger, and the average in some cases was much different from the one estimated from seven instruments. When the number of instrument was six, the average was not so different from one estimated from seven instruments, although the standard deviation tended to be slightly larger.

\section{Inversion Analysis}

We inverted $S$-wave velocity structures based on a Rayleigh-wave inversion technique to minimize the following misfit $J(\{r\})$ using a quasi-Newton method (Fletcher, 1972).
Table 2

Estimated Structure

\begin{tabular}{ccccccccc}
\hline & \multirow{2}{*}{$\begin{array}{c}\text { Layer } \\
\text { No. }\end{array}$} & $\begin{array}{c}\text { V-Wave } \\
(\mathrm{m} / \mathrm{sec})\end{array}$ & $\begin{array}{c}P \text {-Wave } \\
\text { Velocity } \\
(\mathrm{m} / \mathrm{sec})\end{array}$ & $\begin{array}{c}\text { Density } \\
\left(\mathrm{g} / \mathrm{cm}^{3}\right)\end{array}$ & \multicolumn{4}{c}{$\begin{array}{c}\text { Thickness } \\
(\mathrm{m})\end{array}$} \\
\hline 1 & $\mathbf{1 1 6}$ & 1419 & 1.7 & $\mathbf{4}(5)$ & $\mathbf{4}(5)$ & $\mathbf{3}(4)$ & $3(4)$ \\
2 & $\mathbf{2 7 8}$ & 1599 & 1.8 & $\mathbf{0}(2)$ & $\mathbf{1 1}(10)$ & $\mathbf{2 2}(24)$ & $\mathbf{1 4}(8)$ \\
3 & $\mathbf{6 5 7}$ & 2019 & 1.9 & $\mathbf{6 5}(76)$ & $\mathbf{6 7}(76)$ & $\mathbf{0}(0)$ & $\mathbf{7 2}(70)$ \\
4 & $\mathbf{1 1 0 0}$ & 2511 & 2.1 & & $(900)$ & $\mathbf{1 2 0 2}$ & $(1020)$ & $(1370)$ \\
5 & 1580 & 2808 & 2.3 & & $(1800)$ & \\
6 & 2560 & 4551 & 2.5 & & $(2700)$ & \\
7 & 3290 & 5849 & 2.6 & & & & \\
\hline
\end{tabular}

Bold numbers indicate values inverted from phase velocities; parentheses indicate values estimated from HVRs.

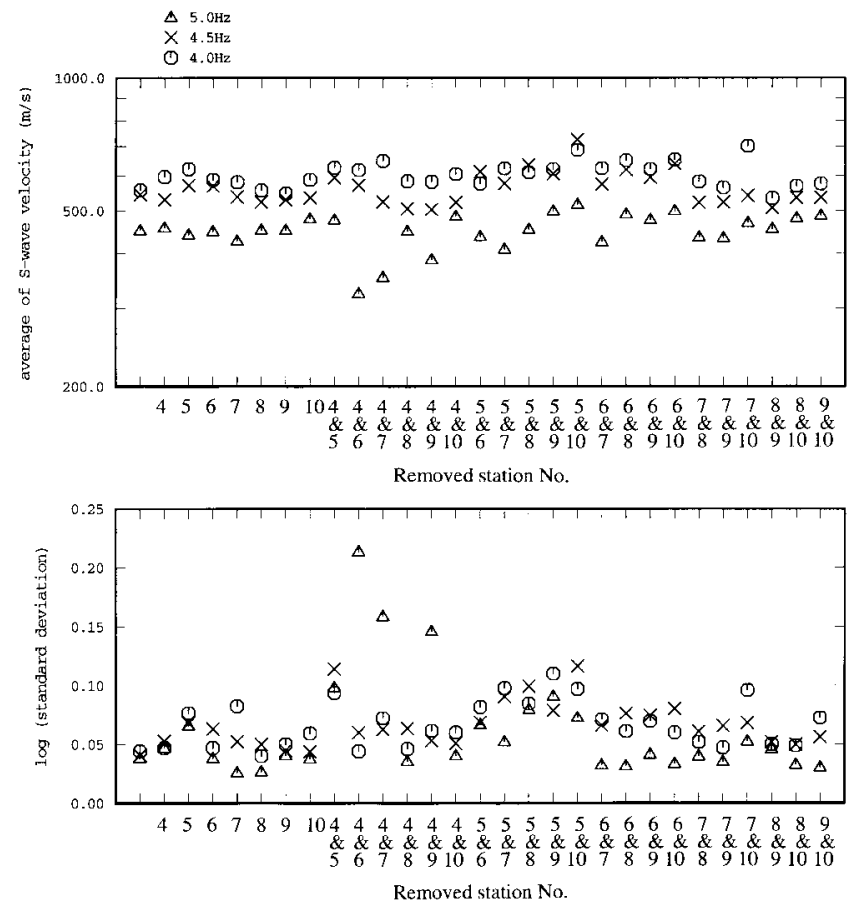

Figure 6. Average and the logarithm of the standard deviation of phase velocity, which are estimated by removing one or two instruments of the $M$ array at TAL002. Horizontal axis is the removed instrument number (See Fig. 3b).

$$
J(\{r\})=\frac{\int_{f s}^{f e} \frac{1}{\mathrm{SD}}\left|c_{\mathrm{o}}(f)-c_{\mathrm{t}}(f,\{r\})\right|^{2} d f}{\int_{f s}^{f e}\left|c_{\mathrm{o}}(f)\right|^{2} d f}
$$

Here $c_{\mathrm{o}}(f)$ and $c_{\mathrm{t}}(f,\{r\})$ are the average of the observed phase velocities and calculated phase velocity for the fundamental Rayleigh wave, respectively. SD is the logarithm of standard deviation of the observed phase velocities and is used as a weighting function. The variables $f s$ and $f e$ are the minimum and maximum frequencies, and $\{r\}$ refers to in- 
verted parameters. The inverted values are shown in Table 2. Except for the $S$-wave velocity of the fourth layers in Table 2, bold numbers were inverted using equation (1).

Figure 7 shows the observed and calculated phase velocities having initial and inverted $S$-wave velocity structures. From $S$-array records at TCU067, phase velocities were estimated successfully only in the frequency range from 5 to $7 \mathrm{~Hz}$ due to a smaller number (five) of instruments (Table 1). Since these phase velocities $(f=5-7 \mathrm{~Hz})$ agreed with those estimated from $M$-array records, we used phase velocities estimated from $M$-array at TCU067 for the inversion. The frequency range of observed phase velocities for each array was determined by minimum and maximum station separations shown in Table 1 . The minimum wavelength we could detect was twice the minimum station separation. This limitation was derived theoretically from the Nyquist wavenumber. The maximum wavelength was empirically considered to be two to seven times the maximum station separation (e.g., Horike, 1985; Matsushima and Okada, 1990; Satoh et al., 2001a). In Figure 7 two oblique lines show the detection limits derived from three and six times the maximum station separation of the largest array at each site. At three sites, observed phase velocities became almost flat with the phase velocity of about $1 \mathrm{~km} / \mathrm{sec}$ in the
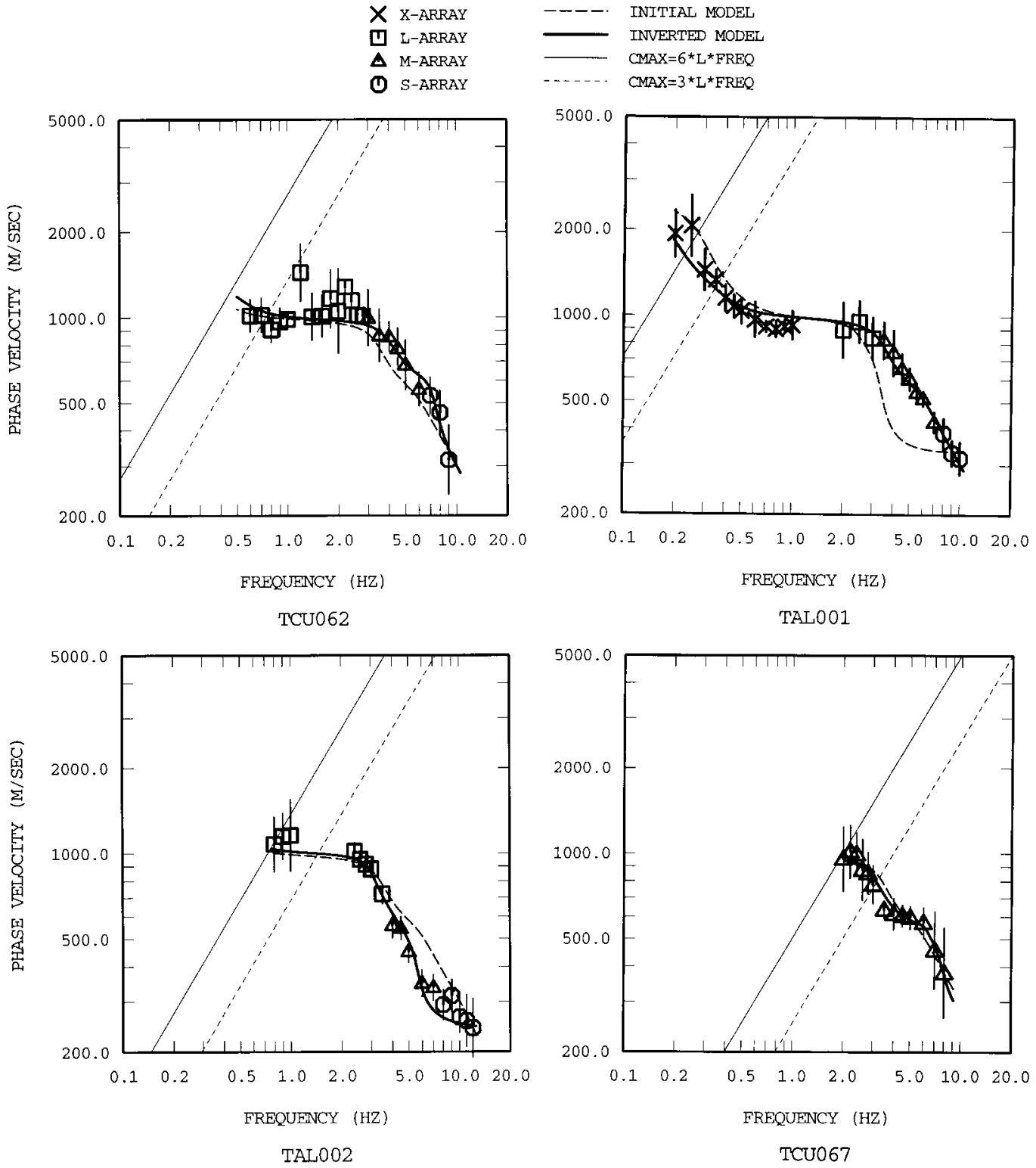

Figure 7. Observed phase velocities of $S$ array (circles), $M$ array (triangles), $L$ array (squares), and $X$ array (multiplication signs) and calculated ones having initial (thick dashed lines) and inverted (thick lines) $S$-wave velocity structures. Average \pm one standard deviations are shown by bars. Thin dashed and continuous oblique lines show three and six times of the maximum station separation of the largest array, respectively. 
wide frequency range from 0.5 to $2 \mathrm{~Hz}$. This suggests that at all three sites, a thick layer with an $S$-wave velocity of about $1 \mathrm{~km} / \mathrm{sec}$ was deposited. The phase velocities in the frequency range from 1 to $2 \mathrm{~Hz}$ could not be estimated at TAL001 and TAL002, and the standard deviation in that frequency was relatively large at TCU062. The main reason is that the Fourier amplitude in this frequency was too small to detect coherently propagating waves (see Fig. 4b). On the other hand, phase velocities of the frequencies lower than 1 $\mathrm{Hz}$ or higher than $2 \mathrm{~Hz}$ could be estimated up to about six times the maximum station separation due to the large spectral amplitudes.

In Table 2, the $S$-wave velocities of the fifth to seventh layers were assumed based on the crustal structure of southwestern Taiwan (Chung and Yeh, 1997). $P$-wave velocities $\left(V_{P}\right)$ of the fifth to seventh layers were calculated using a relation of $V_{P} / V_{S}=1.78$. The thicknesses of the fifth and sixth layers were estimated using peak frequencies of HVRs, as will be explained later. Using the estimated structures of the fifth to seventh layers, we estimated the $S$-wave velocity of the fourth layer to be $1100 \mathrm{~m} / \mathrm{sec}$ by fitting calculated phase velocities to observed ones at TCU062, TCU001, and TAL002 by a forward-modeling procedure. To show the sensitivity of the $S$-wave velocity of the fourth layer, we plotted calculated phase velocities with $S$-wave velocities of 1.2 times and $1 / 1.2$ times the $1100 \mathrm{~m} / \mathrm{sec}$ at the three sites in Figure 8. Here, the other parameters were given constant values shown in Table 2 . The sensitivity of the $S$-wave velocity of the fourth layer was high, and it is confirmed that the phase velocities calculated by using an $S$-wave velocity of $1100 \mathrm{~m} / \mathrm{sec}$ reasonably explained phase velocity data in the frequency range from 1 to $2 \mathrm{~Hz}$ at the three sites.
Then we estimated $S$-wave velocities and thicknesses of the first to third layers and a thickness of the fourth layer at TAL001. Because the highest observed phase velocity was less than about $1000 \mathrm{~m} / \mathrm{sec}$, at TCU062, TAL002, and TCU067, the thicknesses of the fourth layer with $V_{S}=1100$ $\mathrm{m} / \mathrm{sec}$ could not be estimated at three sites. The $P$-wave velocities $\left(V_{P}\right)$ of the first to fourth layers were calculated from $S$-wave velocities $\left(V_{S}\right)$ using an empirical relation of $V_{P}=$ $1.29+1.11 V_{S}$ in $\mathrm{km} / \mathrm{sec}$ (Kitsunezaki et al., 1990). Since we did not have any information on $S$-wave velocity structures for the first to third layers, the same $S$-wave velocity of $V_{S}=350 \mathrm{~m} / \mathrm{sec}$ was assumed in the initial model. Then we inverted $S$-wave velocities and thicknesses of three layers to improve the agreement between observed and calculated phase velocities. The initial thicknesses of the first to fourth layers were $1,4,45$, and $1000 \mathrm{~m}$, respectively. To show the sensitivity of $S$-wave velocities of the first to third layers at TAL001, we plotted calculated phase velocities with $S$-wave velocities of 1.2 times and $1 / 1.2$ times the inverted values in Figure 9 . Here, $P$-wave velocities were changed by the empirical relation proposed by Kitsunezaki et al. (1990).

Once the $S$-wave velocities were obtained, the thicknesses of the first to third layers at the other three sites were inverted by fixing the $S$-wave velocities as obtained at TAL001. Here we used thicknesses inverted at TAL001 as initial values. It was possible to estimate different $S$-wave velocities at each site to improve the agreement with observed and calculated phase velocities. However, we assumed the same $S$-wave velocities at all sites. The main reason was that simple modeling with the same $S$-wave velocities would be more convenient since our final objective of this study was to construct a 3D basin model of the

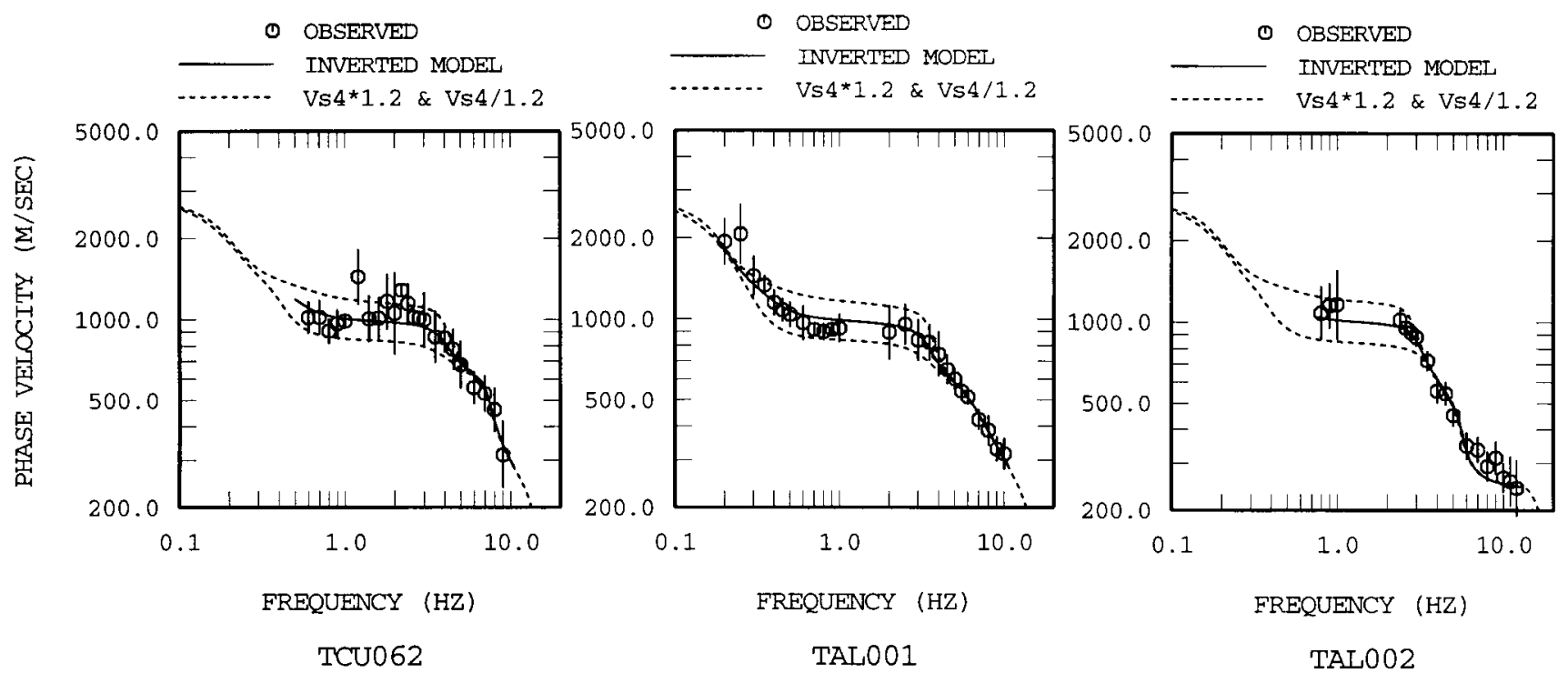

Figure 8. Calculated phase velocities with $S$-wave velocities of 1.2 times and 1/1.2 times of $1100 \mathrm{~m} / \mathrm{sec}$ (dashed lines) at TCU062, TAL001; and TAL002. Observed (circles and vertical bars) and calculated (continuous lines) phase velocities are the same as those shown in Figure 7. 


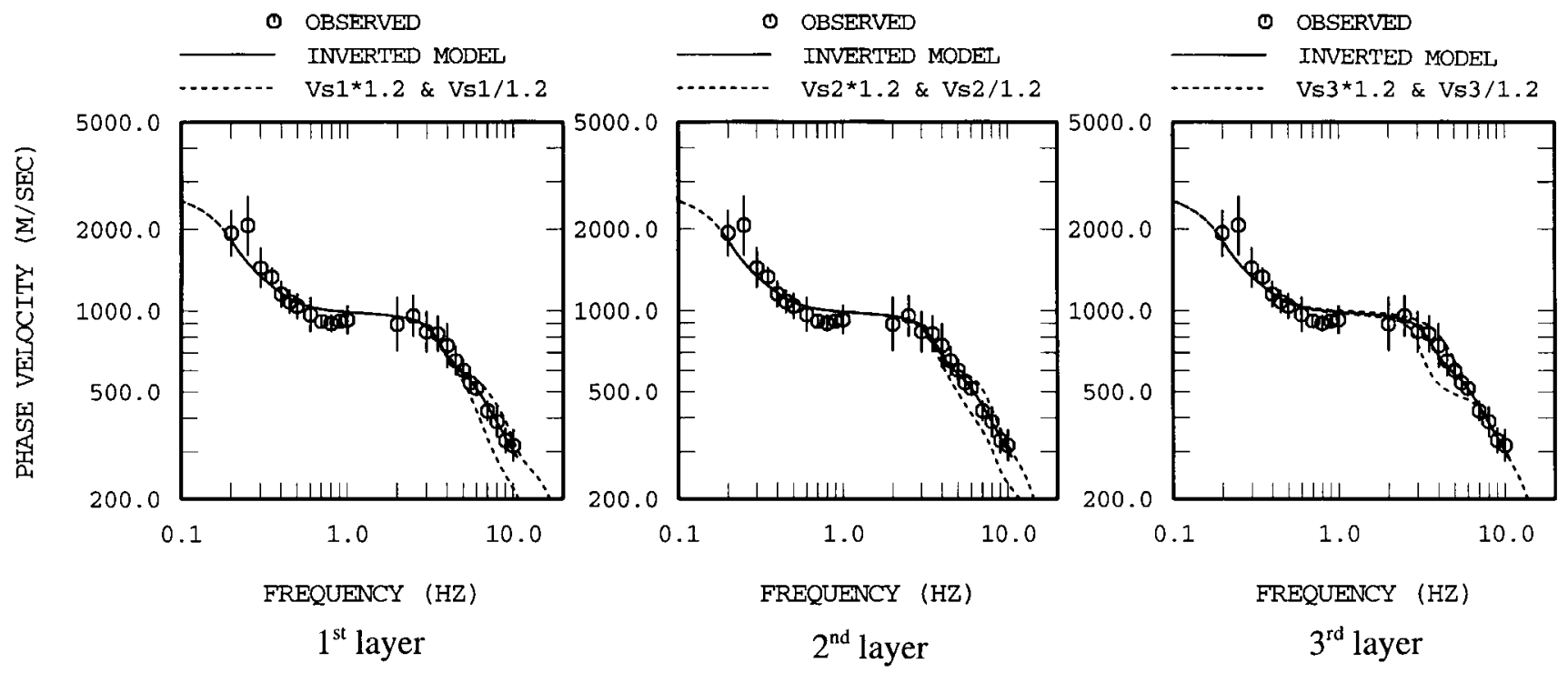

Figure 9. Calculated phase velocities with $S$-wave velocities of 1.2 times and 1/1.2 times of values inverted (dashed lines) for the first, second, and third layers at TAL001. Observed (circles and vertical bars) and calculated (continuous lines) phase velocities are the same as those shown in Figure 7.

Taichung basin needed for theoretical strong-motion evaluation. The other reason was that observed phase velocities had some variation shown by standard deviations and so that it was meaningful to invert structures within such data resolution. The results in Figure 7 indicate that phase velocities corresponding to the inverted $S$-wave velocity structures for the sedimentary layers fitted the observations reasonably.

\section{Estimation of $S$-Wave Velocity Structures Using HVRs of Microtremors}

HVRs at Array and Single-Station Microtremor Sites

Using the subsurface structures inverted from phase velocities, we calculated HVR, that is, ellipticity for the fundamental Rayleigh wave. We used thicknesses estimated from HVRs only if they were not estimated from phase velocities (Table 2). Figure 10 compares the calculated and observed HVRs. The observed HVR at each site is the value averaged over HVRs of $S$-array records in the same way as was done for the $f-k$ analysis. The peak and trough frequencies of calculated HVRs shown by bold dashed lines mostly agree with observed ones. On the other hand, calculated peak and trough amplitudes do not agree with observed ones in the high-frequency range, possibly due to contamination of Love waves in horizontal components. Therefore we used peak and trough frequencies but not the amplitudes for the estimation of thicknesses from HVRs by a method mentioned later. The thin dotted lines denote the calculated HVRs having thicknesses estimated from HVRs. The thicknesses estimated from the phase velocities and HVRs are compared in Table 2. The maximum differences between them are small, that is, within 1,6 , and $11 \mathrm{~m}$ for the first, second, and third
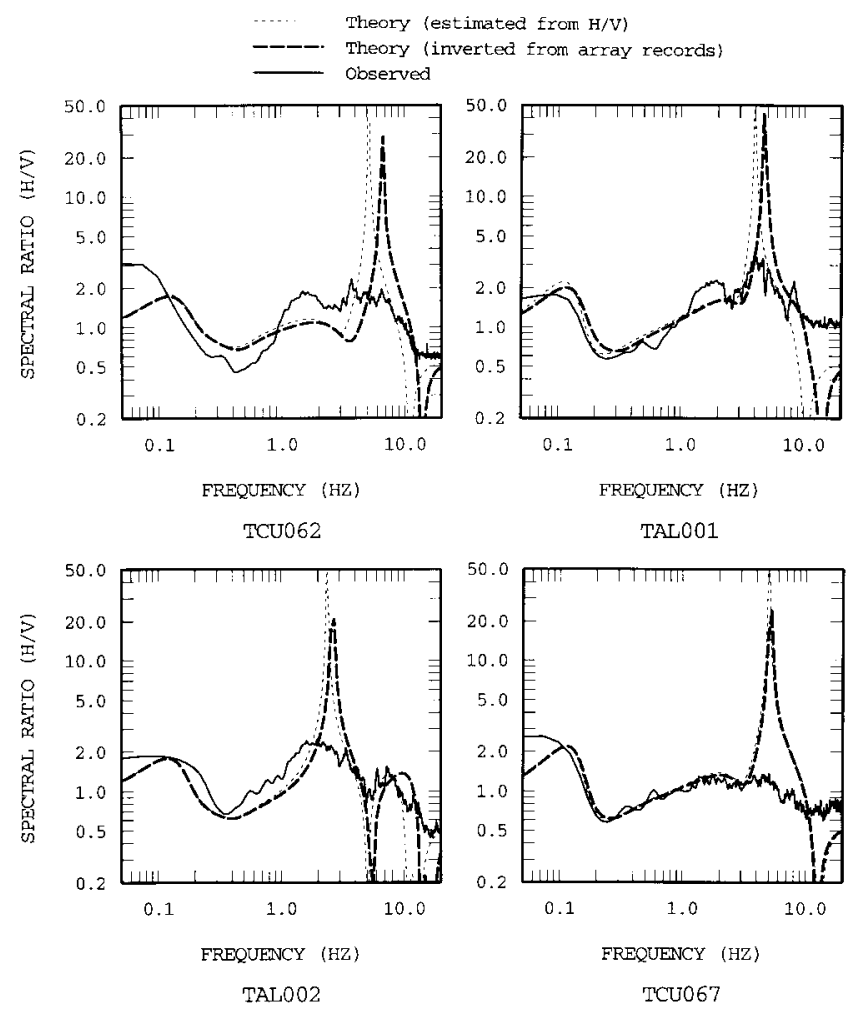

Figure 10. Observed HVRs (solid lines) and calculated ones having structures inverted from phase velocities (bold dashed lines) and estimated HVRs (thick dotted lines). 
layers, respectively. The variation of data themselves and contamination of Love waves in horizontal components may have caused these differences.

Figure 11 shows observed HVRs (solid lines) at singlestation microtremor sites along the three lines, EW-1, EW-2, and NS, shown in Figure 1. Here we calculated HVRs for all the available time segments and averaged them at each site. The HVRs at TCU062, TAL001, TAL002, and TCU067 along the EW-2 line are the same ones shown in Figure 10. The HVRs have common peaks in the frequency range from 0.1 and $0.15 \mathrm{~Hz}$. At most of the sites inside the basin (i.e., below the arrow of the fault line in Fig. 11), the HVRs have troughs in the frequency range from 0.2 to $1 \mathrm{~Hz}$, and peaks at about $1.5 \mathrm{~Hz}$. The dotted lines indicate the calculated HVRs with structures estimated using peak and trough frequencies by a method explained later.

\section{Numerical Experiment and Estimation Method}

We estimated thicknesses of sedimentary layers at the 48 sites to fit the calculated peak and trough frequencies of HVRs for Rayleigh wave to those of observed ones assuming the same $S$-wave velocities estimated from the phase velocities of the array records. To know which layer contributed to observed peak and trough frequencies of HVRs, we conducted a numerical experiment on HVRs for the fundamental Rayleigh wave. Figure $12 \mathrm{a}-\mathrm{e}$ shows HVRs calculated by changing thicknesses of the layers with $V_{S}=1580 \mathrm{~m} / \mathrm{sec}$, and $V_{S}=1100 \mathrm{~m} / \mathrm{sec}, V_{S}=657 \mathrm{~m} / \mathrm{sec}, V_{S}=278 \mathrm{~m} / \mathrm{sec}$, and $V_{S}=116 \mathrm{~m} / \mathrm{sec}$, respectively. Here the other parameters ( $P$-wave velocities, $S$-wave velocities, densities, and thicknesses except for the changing thickness) were fixed by the values estimated from the phase velocities at TAL001. We also assumed the thickness ratio between the layers with $V_{S}$ $=1580 \mathrm{~m} / \mathrm{sec}$ and $V_{S}=2560 \mathrm{~m} / \mathrm{sec}$ to be $2: 3$, which is the same ratio as the inverted thicknesses.

The larger the thickness of the layer with $V_{S}=1580$ $\mathrm{m} / \mathrm{sec}$ was, the lower the peak frequency became from 0.3 to $0.08 \mathrm{~Hz}$. The larger the thickness of the layer with $V_{S}=$ $1100 \mathrm{~m} / \mathrm{sec}$ was, the lower the trough frequency became from 1 to $0.2 \mathrm{~Hz}$. The other peak and trough frequencies did not depend so much on the thickness of the layer with $V_{S}=$ $1580 \mathrm{~m} / \mathrm{sec}$ or $V_{S}=1100 \mathrm{~m} / \mathrm{sec}$, as shown in Figure $12 \mathrm{a}$ and $\mathrm{b}$. In addition, when the thickness of one of the shallower layers with $V_{S}=657 \mathrm{~m} / \mathrm{sec}, V_{S}=278 \mathrm{~m} / \mathrm{sec}$, or $V_{S}=116$ $\mathrm{m} / \mathrm{sec}$ changed, the peak and trough frequencies controlled by the deeper layers with $V_{S}=1580 \mathrm{~m} / \mathrm{sec}$ and $V_{S}=1100$ $\mathrm{m} / \mathrm{sec}$ did not change, as shown in Figure 12c-e. This numerical experiment shows that the thicknesses of the layers with $V_{S}=1580 \mathrm{~m} / \mathrm{sec}$ and $V_{S}=1100 \mathrm{~m} / \mathrm{sec}$ can be independently estimated using the peak and trough frequencies below $1 \mathrm{~Hz}$.

For the layer with $V_{S}=1580 \mathrm{~m} / \mathrm{sec}$, however, the observed peak frequencies at about $0.15 \mathrm{~Hz}$ did not change so much from site to site, as shown in Figure 11. In addition, the observed peaks were not sharp, mainly because the amplitudes in such a low-frequency range were as small as those in the frequency range from 1 to $2 \mathrm{~Hz}$, where coherently propagating waves were difficult to detect by the $f-k$ analysis. Therefore we estimated the common thickness of the layer with $V_{S}=1580 \mathrm{~m} / \mathrm{sec}$ at all the sites by a forwardmodeling procedure.

To estimate the thickness of the layer with $V_{S}=1100$ $\mathrm{m} / \mathrm{sec}$, we calculated HVRs by changing the thickness of this layer from 200 to $1400 \mathrm{~m}$ by a grid spacing of $20 \mathrm{~m}$. Then we selected all trough frequencies in the frequency range from 0.1 to $1.5 \mathrm{~Hz}$ and selected the higher frequency if there were two troughs by considering the numerical experiment shown in Figure 12b. For observed trough frequencies we basically selected the deepest trough in the same frequency range at each site. If the difference of the amplitudes of nearby troughs was less than 0.02 , we took a geometrical average of the two trough frequencies as in the case of WST02 shown in Figure 11a. When the observed trough was not so clear or multiple troughs existed in this frequency range, we selected a trough by considering the numerical experiment and spatial smoothness in the thickness distribution. As shown in Figure 12b, the trough is theoretically unclear when the thickness was less than about $400 \mathrm{~m}$, and so the reliability of the estimated thickness would be lower when the thickness was less than $400 \mathrm{~m}$.

Peak and trough frequencies in the frequency range from 1 to $20 \mathrm{~Hz}$ depend on the layers with $V_{S}=657 \mathrm{~m} / \mathrm{sec}$, $V_{S}=278 \mathrm{~m} / \mathrm{sec}$, and $V_{S}=116 \mathrm{~m} / \mathrm{sec}$ as shown in Figure $12 \mathrm{c}-\mathrm{e}$. The trough frequencies at around $12 \mathrm{~Hz}$ shown in Figure 12c and d do not change so much, so they are mainly controlled by the layer with $V_{S}=116 \mathrm{~m} / \mathrm{sec}$. However, other peak and trough frequencies below $12 \mathrm{~Hz}$ are influenced by multiple layers. Therefore we estimated the thicknesses of the three layers by fitting the calculated peak and trough frequencies to the observed ones in the frequency range from 1 to $20 \mathrm{~Hz}$ by a grid search method. The searching range of the thickness was determined based on the calculated and observed HVRs. The thickness of the layer with $V_{S}=657$ $\mathrm{m} / \mathrm{sec}$ was changed from 0 to $150 \mathrm{~m}$ by a grid spacing of $2 \mathrm{~m}$. The thickness of the layer with $V_{S}=278 \mathrm{~m} / \mathrm{sec}$ was changed from 0 to $30 \mathrm{~m}$ by a grid spacing of $2 \mathrm{~m}$. The thickness of the layer with $V_{S}=116 \mathrm{~m} / \mathrm{sec}$ was changed from 0 to $5 \mathrm{~m}$ by a grid spacing of $1 \mathrm{~m}$.

The number of total grids was $7296(76 \times 16 \times 6)$. Theoretical peak and trough frequencies were automatically selected in the frequency range from 1 to $20 \mathrm{~Hz}$. Observed peak and trough frequencies at each site were selected by sight by considering the numerical experiment and spatial smoothness in the thickness distribution. The circles and triangles in Figure 12 show the observed peak and trough frequencies, respectively. The thicknesses of the three layers were estimated to select $m$ th grid having the smallest values of $E R R^{m}$,

$$
\begin{aligned}
E R R^{m}=\sum_{j=1}^{J_{1}} \operatorname{Min}_{i=1 \rightarrow l_{1}} \frac{i}{j}\left|w_{j} \log \left(T P_{i}^{m} / O P_{j}\right)\right| \\
\\
\quad+\sum_{j=1}^{J_{2}} \operatorname{Min}_{i=1 \rightarrow l_{2}} \frac{i}{j}\left|\log \left(T D_{i}^{m} / O D_{j}\right)\right|
\end{aligned}
$$


$\Delta$ Dip (controlled by Vs $=1100 \mathrm{~m} / \mathrm{s}$ )

$\triangle$ Dip

o Peak (a) EW2-line

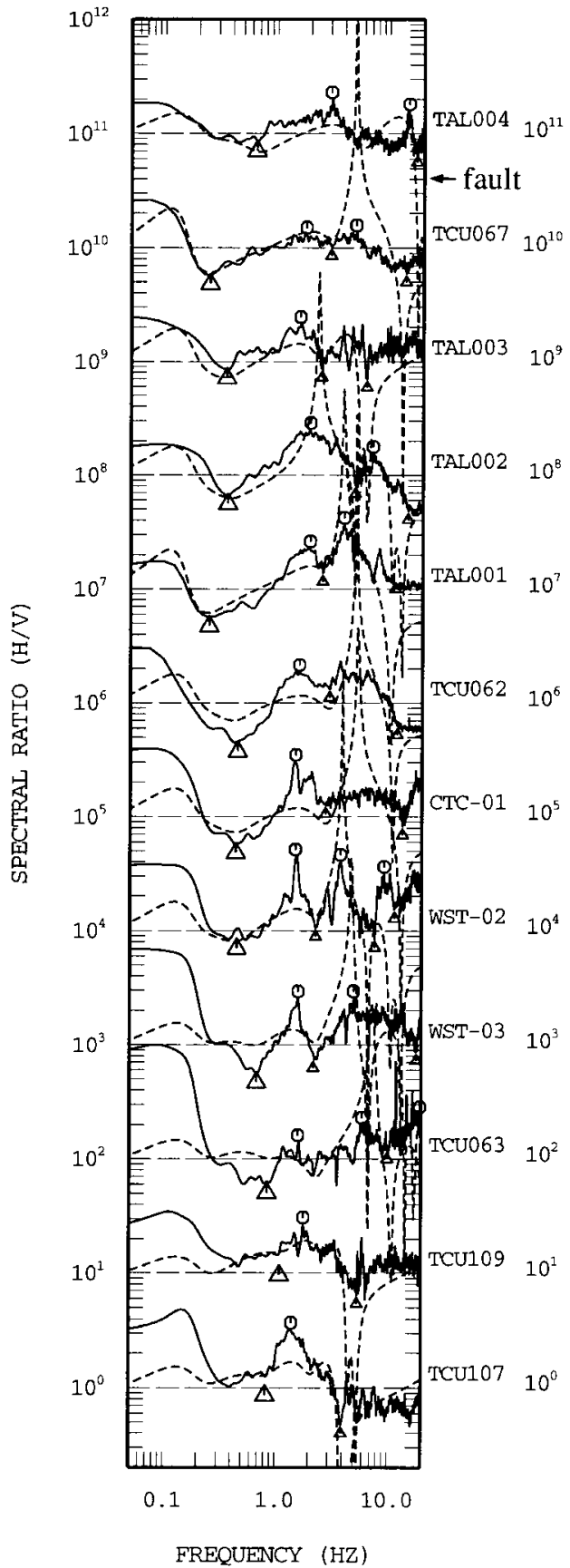

(b) EW1-line

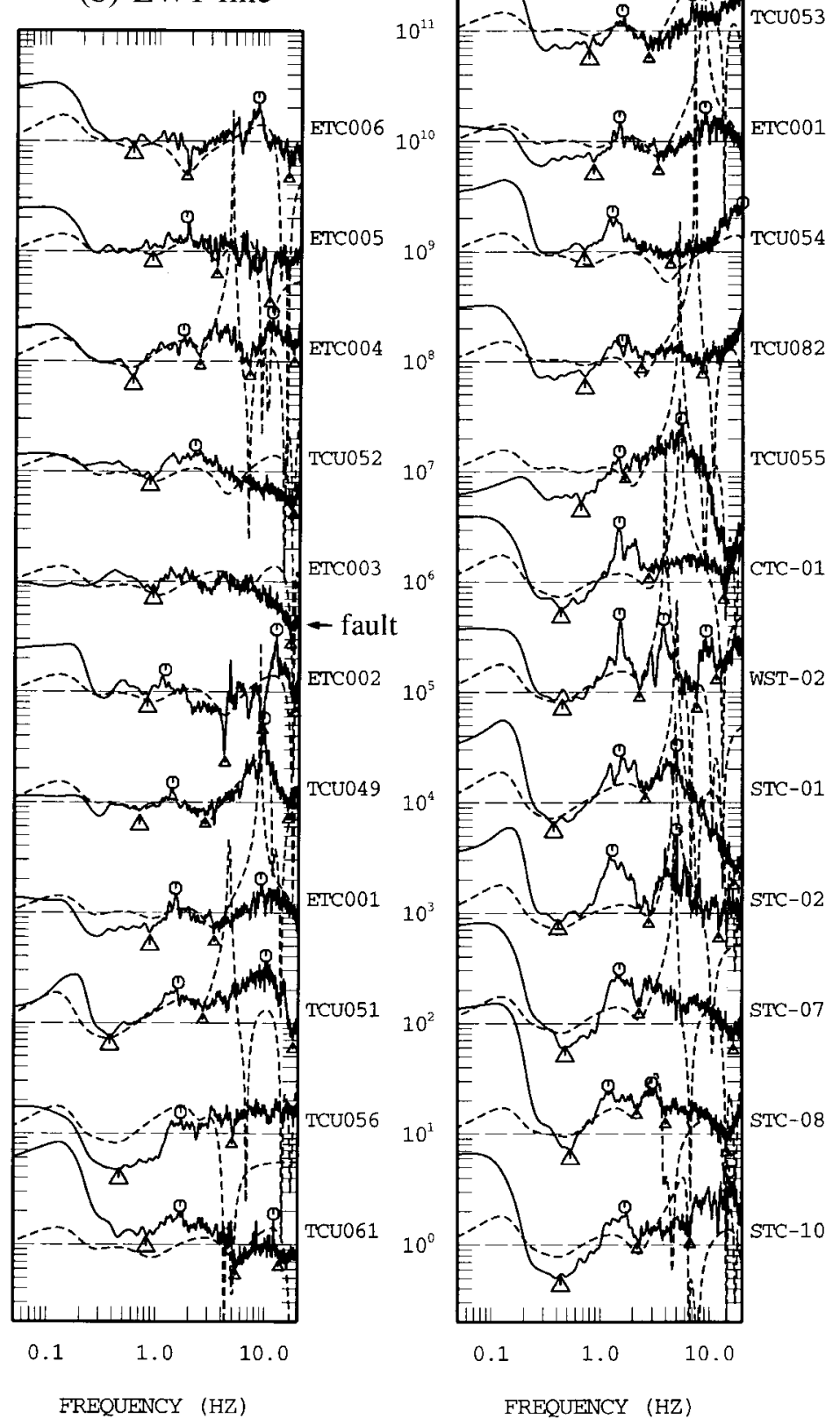

Figure 11. Observed (solid lines) and calculated (thick dashed lines) HVRs at single-station microtremor sites along the three lines: (a) EW2 line, (b) EW1 line, and (c) NS line. Thin dashed lines denote the baseline of a factor of one at each site. Big triangles denote troughs of HVRs used for the estimation of the thickness of the layer with $V_{\mathrm{S}}=1100 \mathrm{~m} / \mathrm{sec}$. Small triangles and circles denote troughs and peaks of HVRs used for the estimation of the thicknesses of the layers with $V_{\mathrm{S}}=657 \mathrm{~m} / \mathrm{sec}, V_{\mathrm{S}}=$ $278 \mathrm{~m} / \mathrm{sec}$, and $V_{\mathrm{S}}=116 \mathrm{~m} / \mathrm{sec}$. 

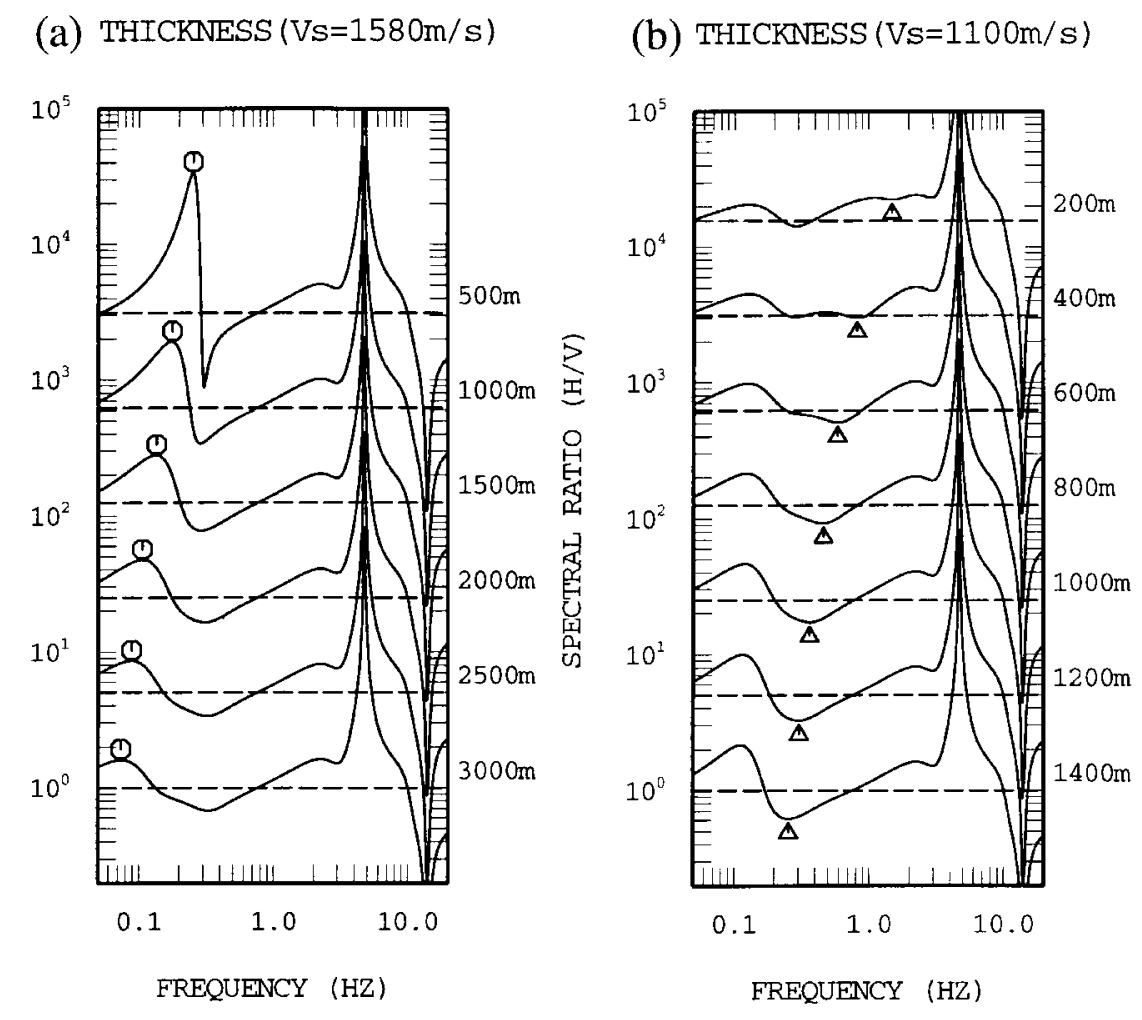

(d) THICKNESS (Vs $=278 \mathrm{~m} / \mathrm{s})$

(c) THICKNESS $(\mathrm{Vs}=657 \mathrm{~m} / \mathrm{s})$

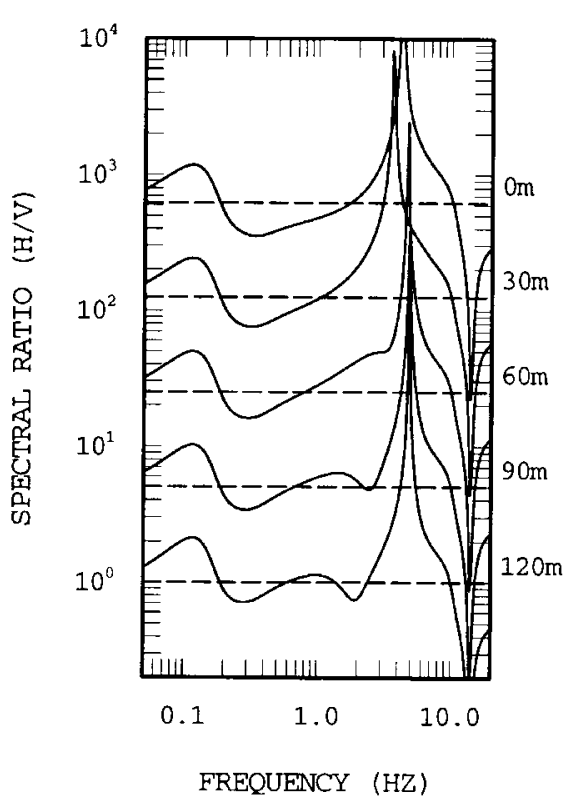

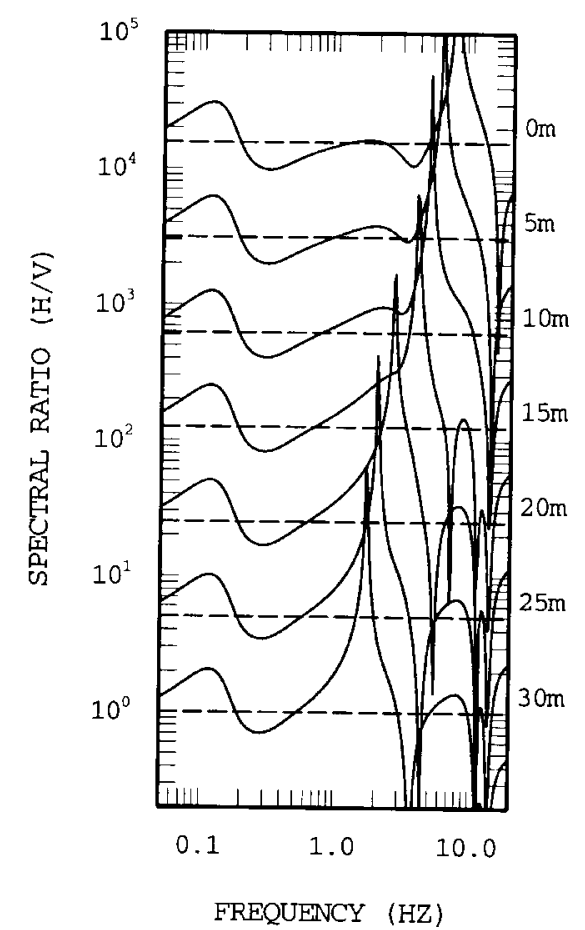

FREQUENCY (HZ)

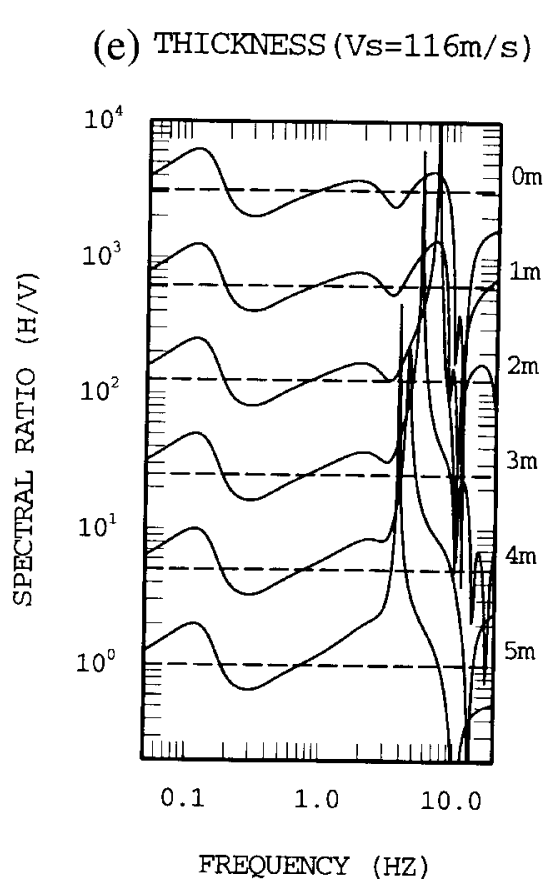

Figure 12. Calculated HVRs by changing thicknesses of the layers with (a) $V_{\mathrm{S}}=$ $1580 \mathrm{~m} / \mathrm{sec}$, (b) $V_{\mathrm{S}}=1100 \mathrm{~m} / \mathrm{sec}$, (c) $V_{\mathrm{S}}=657 \mathrm{~m} / \mathrm{sec}$, (d) $V_{\mathrm{S}}=278 \mathrm{~m} / \mathrm{sec}$, and (e) $V_{\mathrm{S}}=116 \mathrm{~m} / \mathrm{sec}$. Here the other parameters ( $P$-wave velocities, $S$-wave velocities, densities, thicknesses except for the changing thickness) were fixed by the values estimated from the phase velocities at TAL001. Circles denote peak frequencies mainly controlled by the layer with $V_{\mathrm{S}}=1580 \mathrm{~m} / \mathrm{sec}$. Triangles denote trough frequencies mainly controlled by the layer with $V_{\mathrm{S}}=1100 \mathrm{~m} / \mathrm{sec}$. 
Here $T P_{i}^{m}$ and $T D_{i}^{m}$ are the calculated $i$ th peak and trough frequencies for the $m$ th grid, respectively. $I_{1}$ and $I_{2}$ are the number of calculated peaks and troughs in the same frequency range, respectively; $O P_{j}$ and $O D_{j}$ are the observed $j$ th-peak and trough frequencies, respectively; and $J_{1}$ and $J_{2}$ are the number of observed peaks and troughs in this frequency range, respectively. $W_{j}$ is the weighting constant, 0.3 for $j=1$ and 1.0 for everything else. $W_{j}$ was empirically introduced because the first peak frequencies at most of the sites were in the frequency range from 1 to $2 \mathrm{~Hz}$, where Fourier amplitudes are small (Fig. 4). The validity of the method was proved by applying it to the four array measurement sites (Fig. 10).

\section{Estimated Velocity Structure}

The thickness of the layer with $V_{S}=1580 \mathrm{~m} / \mathrm{sec}$ was estimated to be $1800 \mathrm{~m}$ by considering peak frequencies (around $0.15 \mathrm{~Hz}$ ) of HVRs and previous information (Shaw, 1996). When we use this thickness $(1800 \mathrm{~m})$, the lower boundary of this layer at TCU109 (about $2.2 \mathrm{~km}$ ) is consistent with the lower boundary of the Toukoshan Formation in Pleistocene era obtained from a deep well near this site (Shaw, 1996). Since the pre-Tertiary bedrock depth obtained from the deep well there (Shaw, 1996) is about $5 \mathrm{~km}$, the thickness of the layer $V_{S}=2560 \mathrm{~m} / \mathrm{sec}$ should be about 2.6 to $2.7 \mathrm{~km}$. The observed peak frequency of about $0.15 \mathrm{~Hz}$ is generally explained by using the thicknesses of 1800 and $2700 \mathrm{~m}$ for the layers with $V_{S} 1580$ and $V_{S} 2560 \mathrm{~m} / \mathrm{sec}$, respectively, as shown in Figure 11 . Using $1800 \mathrm{~m}$ as the thickness of the layer with $V_{S}=1580 \mathrm{~m} / \mathrm{sec}$, the depth of the upper boundary of the layer with $V_{S}=2560 \mathrm{~m} / \mathrm{sec}$ becomes about $3 \mathrm{~km}$ at four array microtremor sites, as shown in Table 2. This is consistent with the upper boundary of the Pliocene layer (lower boundary of the Toukoshan Formation) estimated from onshore and offshore deep wells in western Taiwan (Shaw, 1996). The pre-Tertiary bedrock depth estimated from microtremors becomes nearly $6 \mathrm{~km}$ near array microtremor sites in the east-central part of the Taichung basin (Table 2).

Troughs controlled by the layer with $V_{S}=1100 \mathrm{~m} / \mathrm{sec}$, shown in Figure 11, are not so clear at ETC006, ETC005, and TCU061 along the EW-1 line, at TCU109 and TCU107 along the EW-2 line, and at CTC-07 along the NS line, so the accuracy of the estimated thickness of this layer would not be so good at these sites. Stations ETC005 and ETC006 are located on the hanging wall of the Chelungpu fault. Stations TCU061, TCU107, and TCU109 are located near the Changhua fault in the western part of the Taichung basin. Station CTC-07 is located in the northern part of the Taichung basin. At most of the other sites inside the basin, calculated peak and trough frequencies of HVRs agree well with observed ones. Comparing the observed HVRs on both sides of the Chelungpu fault along the EW-2 line, the trough frequency at a hanging-wall site, TAL004 is clearly higher than that at a nearby footwall site, TCU067. On the other hand, the differences of the trough frequencies at both sides of the fault along the EW-1 line, ETC002 and ETC003, are not clear. This suggests that a sharp lateral discontinuity exists between TCU062 and TAL004, but not between ETC002 and ETC003.

The spatial distribution of the thicknesses of the layers with $V_{S}=1100 \mathrm{~m} / \mathrm{sec}, V_{S}=657 \mathrm{~m} / \mathrm{sec}, V_{S}=257 \mathrm{~m} / \mathrm{sec}$, and $V_{S}=116 \mathrm{~m} / \mathrm{sec}$ estimated from HVRs at all the 52 sites is shown in Figure 13. The layer with $V_{S}=1100 \mathrm{~m} / \mathrm{sec}$ is thickest, $1000-1400 \mathrm{~m}$, near the array microtremor sites in the east-central part of the Taichung basin. This thickness rapidly decreases to less than $400 \mathrm{~m}$ in the northeastern and western parts inside the basin. The difference in thickness on the two sides of the fault is noticeable along the EW-2 line but not along the EW-1 line as suggested from trough frequencies. The difference in the lower boundary of the layer with $V_{S}=1100 \mathrm{~m} / \mathrm{sec}$ is estimated to be about $800 \mathrm{~m}$ between TCU067 and TAL004 (1370 m versus $560 \mathrm{~m})$. These results suggest that lateral discontinuity exists at both eastern and northern sides of array microtremor sites in the east-central part of the basin. However, we should note that these thicknesses were estimated under the assumption that $S$-wave velocities are common at all the sites. Since the Chelungpu fault is a thrust fault dipping to the east, this assumption may not be true at sites on the hanging-wall sides.

The thickness of the layer with $V_{S}=657 \mathrm{~m} / \mathrm{sec}$ is about 60 to $100 \mathrm{~m}$ inside the basin. The thicknesses of the layer with $V_{S}=278$ and $116 \mathrm{~m} / \mathrm{sec}$ are small in the northeastern part and large in the southern and east-central parts. Thus in the northeastern part inside the basin, the thicknesses of the layers with $V_{S}=1100 \mathrm{~m} / \mathrm{sec}$ and the soft layers with $V_{S}=$ $278 \mathrm{~m} / \mathrm{sec}$ and $V_{S}=116 \mathrm{~m} / \mathrm{sec}$ are smaller than those at the other sites inside the basin. It is quite interesting to see that near the array microtremor sites in the east-central part of the basin where we observed high damage concentration during the mainshock, those three layers are relatively thick. The estimated basin structure shown in Figure 13 suggests that it is spatially very complex, and so its $3 \mathrm{D}$ site effects should be taken into account for strong-motion evaluation in the Taichung basin.

\section{Travel-Time Analysis}

We examined the arrival times of the initial $P$ and $S$ waves using records of an aftershock with a magnitude of M 5.5 and a focal depth of $13.5 \mathrm{~km}$ (Fig. 1), which was the only aftershock recorded at all 10 stations deployed by Higashi et al. (2001). In Figure 14, the relationship between the observed travel time and the epicentral distance is shown by circles. The epicentral distance and the travel time were calculated based on the epicenter and the origin time determined by CWB. Using the estimated velocity structures, we calculated the propagating time from the lower boundary of the layer with $V_{S}=1100 \mathrm{~m} / \mathrm{sec}$ to the surface assuming vertical incident $P$ and $\mathrm{S}$ waves. We estimated incident angles from particle orbits of $S$ waves with durations of $2 \mathrm{sec}$ using radial and vertical components. The incident angle av- 

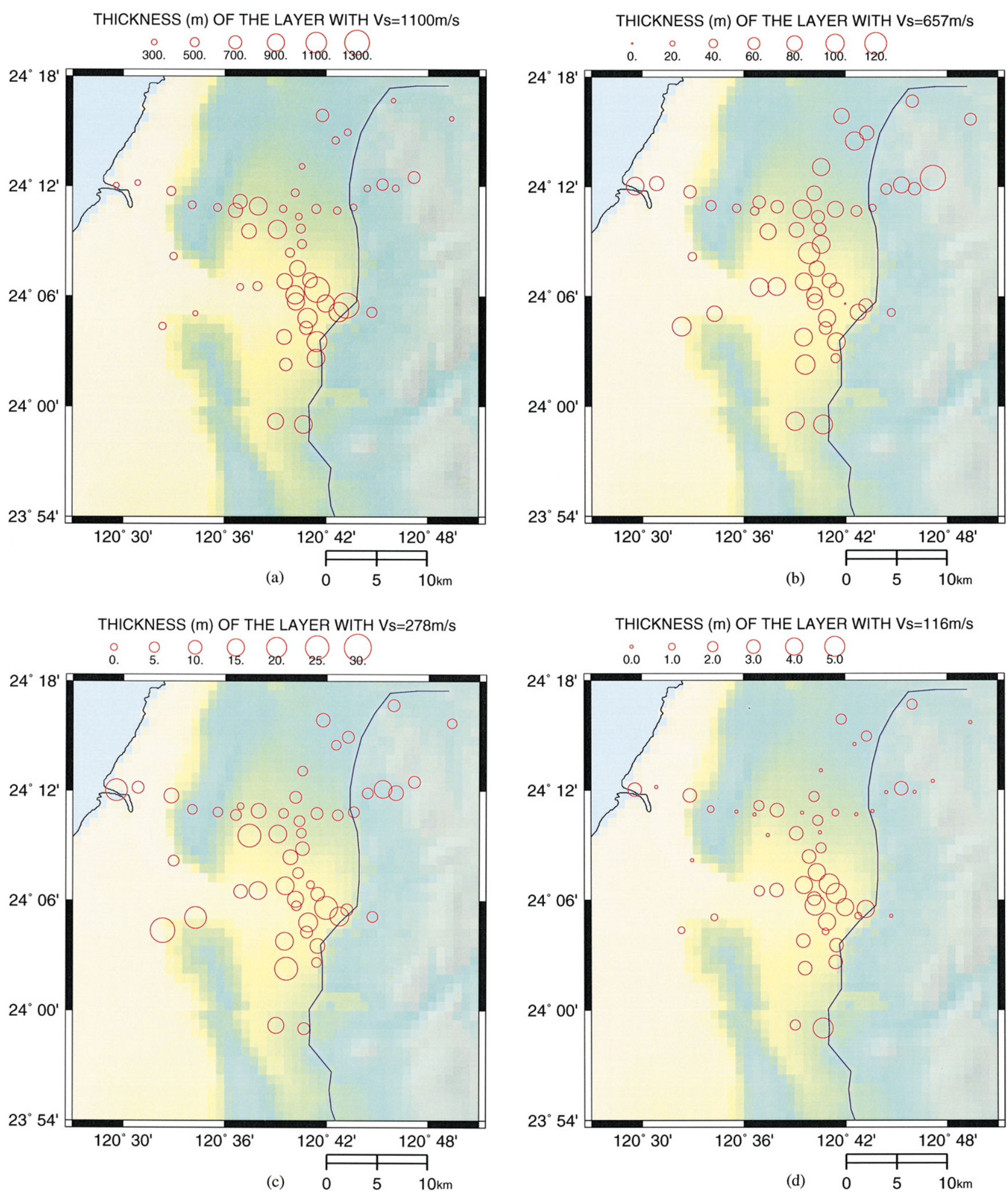

Figure 13. Spatial distribution of the thicknesses of the layers with (a) $V_{\mathrm{S}}=1100$ $\mathrm{m} / \mathrm{sec}$, (b) $V_{\mathrm{S}}=657 \mathrm{~m} / \mathrm{sec}$, (c) $V_{\mathrm{S}}=257 \mathrm{~m} / \mathrm{sec}$, and (d) $V_{\mathrm{S}}=116 \mathrm{~m} / \mathrm{sec}$ estimated from HVRs. 

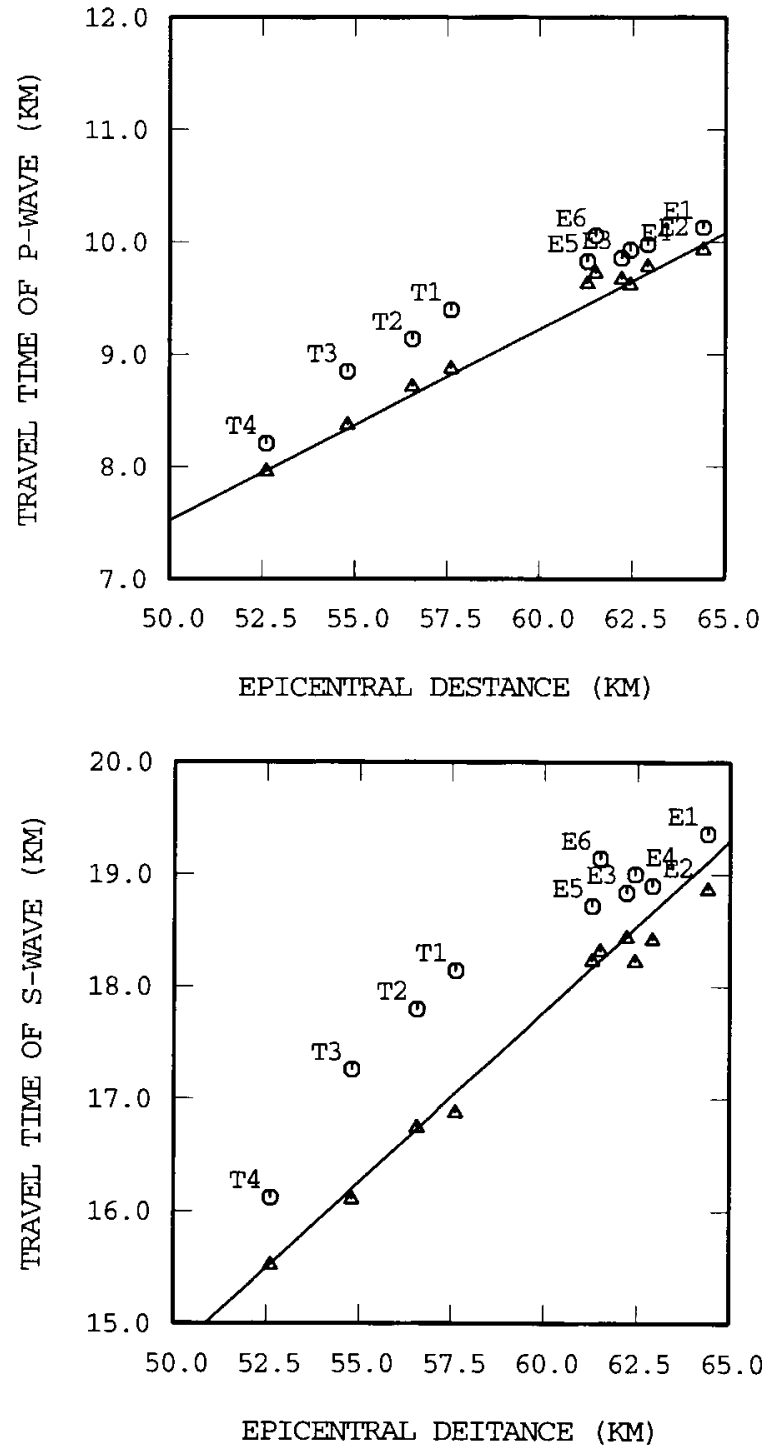

Figure 14. Relation (circles) between the observed travel time of $P$ and $S$ waves and epicentral distance for an aftershock $(M=5.5)$ observed at 10 aftershock strong motion stations (Higashi et al., 2001). T1, T2, T3, T4, E1, E2, E3, E4, E5, and E6 denote TAL001, TAL002, TAL003, TAL004, ETC001, ETC002, ETC003, ETC004, ETC005, and ETC006, respectively. Using the estimated velocity structures, we calculate the propagation time from the lower boundary of the layer with $V_{\mathrm{S}}=1100 \mathrm{~m} / \mathrm{sec}$ to the surface assuming vertical incident $P$ and $S$ waves. Triangles denote the travel time corrected by subtracting the propagating time from the observed travel time from the source to the station. Lines denote calculated travel time with $V_{\mathrm{P}}=5849 \mathrm{~m} / \mathrm{sec}$ and $V_{\mathrm{S}}=3290 \mathrm{~m} / \mathrm{sec}$ of the bedrock to intersect the corrected travel time at TAL004 (T4). eraged over 10 stations was $5.5^{\circ}$, and the standard deviation was $2.8^{\circ}$. So no ray tracing was performed for simplicity. In Figure 14, the triangles denote the travel time corrected by subtracting the propagating time from the observed travel time from the source to the station. We drew calculated travel-time lines with $V_{P}=5849 \mathrm{~m} / \mathrm{sec}$ and $V_{S}=3290 \mathrm{~m} /$ sec of the bedrock (Table 2) to intersect the corrected travel time at TAL004 (T4). The corrected travel time was consistent with the theoretical travel time. If the thickness from the bedrock to the lower boundary of the layer with $V_{S}=1100$ $\mathrm{m} / \mathrm{sec}$ can be assumed to be the same at all 10 stations, this agreement would show the validity of the estimated velocity structures above the layer with $V_{S}=1100 \mathrm{~m} / \mathrm{sec}$.

Using aftershock records, Higashi et al. (2001) showed that site amplifications with respect to TAL004 were noticeable at TAL001, TAL002, and TAL003 along the EW-2 line, but not at ETC001, ETC002, ETC003, ETC004, ETC005, and ETC006 along the EW-1 line. The differences between these observed site amplifications may be due to the differences in the underground structures along these two lines described in this article.

\section{Conclusions}

The objective of this study was to estimate the $S$-wave velocity structure of the Taichung basin in the near-fault region, which is needed for strong-motion evaluation for the Chi-Chi earthquake. To achieve this goal, we have conducted array measurements of microtremors with a total of 12 arrays at four sites and single-station measurements of microtremors at 48 sites in and around the Taichung basin. Based on the Rayleigh-wave inversion technique using phase velocities estimated from array records of microtremors, we find that a thick layer with $V_{S}=1100 \mathrm{~m} / \mathrm{sec}$ is about 1000 to $1400 \mathrm{~m}$ at array microtremor sites. Above this layer, soft layers with $V_{S}=657 \mathrm{~m} / \mathrm{sec}, V_{S}=278 \mathrm{~m} / \mathrm{sec}$, and $V_{S}=116 \mathrm{~m} / \mathrm{sec}$ have been deposited with thicknesses of less than 70,20, and $5 \mathrm{~m}$, respectively.

We estimated the thicknesses of sedimentary layers above the pre-Tertiary bedrock at 48 sites to fit calculated peak and trough frequencies of horizontal-to-vertical spectral ratios of Rayleigh wave to observed ones, assuming the same $S$-wave velocities estimated using array records. The pre-Tertiary bedrock depth was estimated to be about 5 to 6 $\mathrm{km}$ in this region. It is found that the layer with $V_{S}=1100$ $\mathrm{m} / \mathrm{sec}$ is thickest around the array microtremor sites in the east-central part of the basin and that the thickness rapidly decreases to less than $400 \mathrm{~m}$ in the northeastern and western parts inside the basin. The difference in the thicknesses at the two sides of the Chelungpu fault is noticeable along the southern line across the fault (EW2) but not along the northern line (EW-1). The difference in the lower boundary of the layer with $V_{S}=1100 \mathrm{~m} / \mathrm{sec}$ is estimated to be about $800 \mathrm{~m}$ at EW-2. The estimated $S$-wave velocity structures reasonably explain arrival time of initial $P$ and $S$ waves of aftershock records observed by Higashi et al. (2001). 
We should note that the thicknesses were estimated under the assumption that $S$-wave velocities of sedimentary layers were common at all the sites, and only their thicknesses were varying. This assumption might not be true at sites on the hanging wall. However, since most of the singlestation microtremor sites are located at the footwall side inside the basin, the estimated velocity structures would be useful for constructing an initial 3D basin model for strongmotion evaluation.

As pointed out by Sato et al. (1999), it is very important for quantitative strong-motion evaluation to modify the initial basin model estimated by geophysical exploration methods through waveform modeling of strong-motion records for a moderate earthquake. It would be worthwhile to consider an initial 3D basin based on the velocity structures estimated in this study and modify it using waveform modeling of aftershock records in order to construct a realistic 3D model for strong-motion evaluation for the Chi-Chi earthquake.

\section{Acknowledgments}

Microtremor measurements were conducted with Ken'ichiro Nagato, Jun'ichi Miyakoshi, Hiroshi Yajima, and Kazuhiko Ishihara. We especially wish to thank Kazuyoshi Kudo for kindly loaning us seven sets of instruments, Hung-Chie Chiu, Jin Anshu, Haruko Sekiguchi, Yasuhiro Hayashi, Saburoh Midorikawa, and Ingemar Johanson gave us useful suggestions for selecting observation sites. We also appreciate the valuable comments and suggestions of two reviewers. Finally, we used Generic Mapping Tools (GMT) by Wessel and Smith (1998) to plot some figures.

\section{References}

Aki, K. (1957). Space and time spectra of stationary stochastic waves with special reference to microtremors, Bull. Earthquake Res. Inst. Tokyo Univ. 35, 415-457.

Capon, J. (1969). High-resolution frequency-wave-number spectrum analysis, Proc. IEEE 57, 1408-1418.

Chung, J. K., and Y. T. Yeh (1997). Shallow Crestar structure from short period Rayleigh-wave dispersion data in southwestern Taiwan, Bull. Seism. Soc. Am. 87, 370-382.

Fletcher, R. (1972). FORTRAN subroutines for minimization by quasiNewton methods, Report R7125 AERE, Harwell, England.

Graves, R. W. (1996). Simulating realistic earthquake ground motions in regions of deep sedimentary basins, in Proc. of the 11th World Conference on Earthquake Engineering, Acapluco, Mexico, August, CDROM, No. 1932.

Higashi, S., T. Iwata, H. Kawase, T. Satoh, T. Sato, K. Irikura, and H. C. Huang (2001). Aftershock Observation in the Taichung Basin, Bull. Seism. Soc. Am. (in press).

Horike, M. (1985). Inversion of phase velocity of long-period microtremors to the S-wave-velocity structure down to the basement in urbanized areas, J. Phys. Earth 33, 59-96.

Ishida, H., T. Nozawa, and M. Niwa (1998). Estimation of deep surface structure based on phase velocities and spectral ratios of long-period microtremors, in Proc. of the 2nd International Symposium on Effects of Surface Geology on Seismic Motions, Odawara, Japan, 1-3 December, Vol. 2, 697-704.

Iwata, T., H. Sekiguchi, A. Pitarka, K. Kamae, and K. Irikura (1998). Evaluation of strong ground motions in the source area during the 1995 Hyogoken-Nanbu (Kobe) earthquake, in Proc. of the 10th Japan
Earthquake Engineering Symposium, Yokohama, Japan, 25-27 November, Vol. 1, 73-78.

Kawase, H., and S. Matsushima (1998). Strong motion simulation in Kobe during the Hyogo-ken Nanbu earthquake of 1995 based on a threedimensional basin structure, J. Struct. Constr. Eng. Trans. Architectural Inst. Japan 514, 111-118 (in Japanese with English abstract).

Kawase, H., T. Satoh, T. Iwata, and K. Irikura (1998). S-wave velocity structures in the San Fernando and Santa Monica areas, in Proc. of the 2nd International Symposium on Effects of Surface Geology on Seismic Motions, Yokohama, Japan, 1-3 December, Vol. 2, 733-740.

Kitsunezaki, C., N. Goto, Y. Kobayashi, T. Ikawa, M. Horike, T. Saito, T. Kurota, K. Yamane, and K. Okuzumi (1990). Estimation of P- and Swave velocities in deep soil deposits for evaluating ground vibrations in earthquake, J. JSNDS 9, 1-17 (in Japanese with English abstract).

Kudo, K. (1998). Design and manufacture of potable strong motion instrument for array observation and observation/analysis manual, Grantin-Aid for Scientific Research (A), pp. 175 (in Japanese with English abstract).

Kudo, K., T. Kanno, H. Okada, O. Ozel, M. Takahashi, T. Sasatani, S. Higashi, and K. Yoshida (2000). Site effects on strong ground motions during the Kocaeli, Turkey earthquake of August 17, 1999 as inferred from $\mathrm{S}$-wave velocity structures estimated from $\mathrm{S}$-wave velocity structures estimated by array microtremor observations, Western $\mathrm{Pa}-$ cific Geophysics Meeting, EOS Trans. Am. Geophys. Union 81, no. 22, S51F-12.

Lee, J. H., C. Y. Lu, H. T. Chu, B. Delcaillau, J. Angelier, and B. Deffontaines (1996). Active deformation and paleostress analysis in the Pakua anticline area of western Taiwan, Terrestrial, Atmospheric and Oceanic Sciences 7, 431-446.

Matsushima, T., and H. Okada (1990). Determination of deep geological structures under urban areas using long-period microtremors, ButsuriTansa 43, 21-33.

Nakamura, Y. (1988). A method for dynamic characteristics estimation of surface layers using microtremor on the surface, RTRI Report 4, 18 27 (in Japanese with English abstract).

Okada, H., T. Matsushima, T. Moriya, and T. Sasatani (1990). An exploration technique using long-period microtremors for determination of deep geological structures under urbanized areas, Butsuri-Tansa $\mathbf{4 3}$, 402-417 (in Japanese with English abstract).

Pitarka, A., K. Irikura, T. Iwata, and H. Sekiguchi (1998). Three-dimensional simulation for the near-fault ground motion for the $1995 \mathrm{Hy}-$ ogo-ken Nanbu (Kobe), Japan, earthquake, Bull. Seism. Soc. Am. 88, $428-440$.

Sato, T., H. Kawase, M. Matsui, and S. Kataoka (1991). Array measurement of high frequency microtremors for underground structure estimation, in Proc. of the 4th International Conference on Seismic Zonation, Stanford, California, 25-29 August, Vol. 2, 409-416.

Sato, T., R. W. Graves, and P. G. Somerville (1999). 3-D finite-difference simulations of long-period strong motions in the Tokyo metropolitan area during the 1990 Odawara earthquake $\left(M_{J} 5.1\right)$ and the great 1923 Kanto earthquake $\left(M_{S} 8.2\right)$ in Japan, Bull. Seism. Soc. Am. 89, 579607.

Satoh, T., H. Kawase, and S. Matsushima (2001a). Estimation of $S$-wave velocity structures in and around the Sendai basin, Japan, using array records of microtremors, Bull. Seism. Soc. Am. 91, 206-218.

Satoh, T., H. Kawase, and S. Matsushima (2001b). Differences between site characteristics obtained from microtremors, $S$-waves, $P$-waves, and codas, Bull. Seism. Soc. Am. 91, 313-334.

Satoh, T., H. Kawase, T. Sato, and A. Pitarka (2001c). 3D finite-difference waveform modeling of strong motions observed in the Sendai basin, Japan, Bull. Seism. Soc. Am. 91, no. 4, 812-825.

Shaw, C. L. (1996). Stratigraphic correlation and isopach maps of the western Taiwan basin, Terrestrial, Atmospheric and Oceanic Sciences 7, 333-360.

Shin, T. C., K. W. Kuo, W. H. K. Lee, T. L. Teng, and Y. B. Tsai (2000). A preliminary report on the 1999 Chi-Chi (Taiwan) earthquake, Seism. Res. Lett. 71, 24-30. 
Thompson, W. R. (1935). On a criterion for the rejection of observations and the distribution of the ratio of deviation to sample standard deviation, Ann. Math. Stats. 6, 214.

Tokimatsu, K., and Y. Miyadera (1992). Characteristics of Rayleigh waves in microtremors and their relation to underground structures, J. Struct. Constr. Eng. Trans. Architectural Inst. Japan 439, 81-87 (in Japanese with English abstract).

Wessel, P., and W. H. F. Smith (1998). New, improved version of Generic Mapping Tools released, EOS Am. Geophys. Union 79, 579.

Wu, Y. M., C. C. Chen, J. K. Chung, and T. C. Shin (1997). Taiwan rapid earthquake information release system, Seism. Res. Lett. 68, 931-943.

Yamanaka, H., M. Takemura, H. Ishida, and M. Niwa (1994). Characteristics of long-frequency microtremors and their applicability in exploration of deep sedimentary layers, Bull. Seism. Soc. Am. 84, 18311841.

Izumi Research Institute

Shimizu Corporation

2-2-2, Uchisaiwai-cho

Chiyoda-ku, Tokyo 100-0011, Japan

(T. S., T. S.)
Department of Architecture and Urban Design

Graduate School of Human-Environment Studies, Kyushu University 6-10-1, Hakozaki

Higashi-Ku, Fukuoka 812-8581, Japan

(H. K.)

Disaster Prevention Research Institute, Kyoto University Gokasho, Uji

Kyoto 611-0011, Japan

(T. I., K. I.)

Geotechnical and Earthquake Engineering Department Central Research Institute of Electric Power Industry Abiko 1646, Abiko, Chiba 270-1194, Japan

(S. H.)

Institute of Seismology, National Chung-Cheng University No. 160 San-Hsing, Ming-Hsiung.

Chia-Yi 621, Taiwan

(H. H.) 